IZA DP No. 10236

The Decision to Carry:

The Effect of Crime on Concealed-Carry Applications

Briggs Depew

Isaac D. Swensen

September 2016

Forschungsinstitut

zur Zukunft der Arbeit

Institute for the Study

of Labor 


\title{
The Decision to Carry: The Effect of Crime on Concealed-Carry Applications
}

\author{
Briggs Depew \\ Louisiana State University \\ and IZA \\ Isaac D. Swensen \\ Montana State University
}

\section{Discussion Paper No. 10236 \\ September 2016}

\author{
IZA \\ P.O. Box 7240 \\ 53072 Bonn \\ Germany \\ Phone: +49-228-3894-0 \\ Fax: +49-228-3894-180 \\ E-mail: iza@iza.org
}

\begin{abstract}
Any opinions expressed here are those of the author(s) and not those of IZA. Research published in this series may include views on policy, but the institute itself takes no institutional policy positions. The IZA research network is committed to the IZA Guiding Principles of Research Integrity.

The Institute for the Study of Labor (IZA) in Bonn is a local and virtual international research center and a place of communication between science, politics and business. IZA is an independent nonprofit organization supported by Deutsche Post Foundation. The center is associated with the University of Bonn and offers a stimulating research environment through its international network, workshops and conferences, data service, project support, research visits and doctoral program. IZA engages in (i) original and internationally competitive research in all fields of labor economics, (ii) development of policy concepts, and (iii) dissemination of research results and concepts to the interested public.
\end{abstract}

IZA Discussion Papers often represent preliminary work and are circulated to encourage discussion. Citation of such a paper should account for its provisional character. A revised version may be available directly from the author. 
IZA Discussion Paper No. 10236

September 2016

\section{ABSTRACT \\ The Decision to Carry: The Effect of Crime on Concealed-Carry Applications}

Despite contentious debate on the role of concealed-carry legislation in the U.S., little is known about individual decisions to legally carry concealed handguns in public. Using data on concealed-carry permit applications from 1998 to 2012, we explore the degree to which individuals respond to crime by applying for permits to legally carry concealed firearms. We find that recent homicide incidents increase concealed-carry applications in areas relatively near to the event. Our main results suggest that an additional homicide in relatively small cities increases applications by 26 percent over the following two months. We also find effects in larger cities when using neighborhood-level data. Our data allow us to explore specific circumstances of crime incidents and the characteristics of responsive applicants. Our results show that gun-related homicides are particularly relevant and that whites and males are most responsive to homicide incidents. We also find evidence that individuals are more responsive to homicide incidents when they share a common characteristic with the victim, particularly for female applicants.

JEL Classification: K42, I18

Keywords: concealed carry, right to carry, crime, precautionary behavior, gun control, demand for guns

Corresponding author:

Briggs Depew

Department of Economics

Louisiana State University

Baton Rouge, LA70803-6306

USA

E-mail: bdepew@Isu.edu 


\section{Introduction}

The presence of concealed handguns in public spaces is a divisive issue central to ongoing gun-control debates. Every state in the U.S. has legislated a permit application process whereby citizens can legally carry a concealed firearm in public and estimates indicate that the number of concealed-carry permit holders has increased from 2.7 million in 1999 to 12.8 million in 2015 (Lott et al., 2015). More recently, states have expanded concealedcarry policies by relaxing restrictions on permit holders or removing restrictions on "gun free" zones. For instance, since 2013 at least 36 states have introduced highly contested legislation to allow some form of concealed carrying on college campuses $\}^{1}$

The prevalence of concealed-carry legislation and limited data on gun ownership have resulted in an intense scrutiny of concealed-carry laws and a large body of research showing mixed results of the reduced-form effect of these laws on crime $2^{2}$ While the implications of legal concealed carrying have generated considerable interest from researchers and policymakers alike, it is surprising that the determinants of the decision to legally carry a concealed firearm largely remain in the periphery of rigorous quantitative analysis. In this paper we deviate from the large literature analyzing the reduced-form effect of concealed-carry laws on crime by instead considering whether individuals respond to crime by applying for permits to legally carry a concealed firearm.

To do so, we use unique concealed-carry application data from North Carolina spanning 1998 to 2012 to analyze the effect of crime on the number of applications for concealedcarry permits. We initially focus on homicides using North Carolina vitality data, but

\footnotetext{
${ }^{1}$ According to the National Conference of State Legislatures, 18 states ban concealed carrying on college campuses, 22 states leave the decision to each college or university, 8 states specifically allow concealed carrying on college campuses, and the remaining two states have mixed laws. Several other examples of recent concealed carry legislation have been in Washington D.C. California, Kansas, and South Carolina.

${ }^{2}$ See for instance Lott and Mustard (1997); Lott (1998); Bronars and Lott (1998); Dezhbakhsh and Rubin (1998); Black and Nagin (1998); Ludwig (2000); Olson and Maltz|(2001); Moody (2001); Mustard (2001); Plassmann and Tideman (2001); Ayres and Donohue (2003); Durlauf et al. (2016).
} 
also analyze crime more generally using the FBI's Uniform Crime Reports. Our empirical strategy exploits monthly variation in the timing of recent crime incidents, most notably homicides. Intuitively, our approach compares the number of applications in months with recent homicide incidents to months without recent homicide incidents within the same year for a given city after controlling for differences that are expected across different months of the year and trends in applications.

We find that recent homicides increase concealed-carry applications for residents living nearby the homicide incident. Specifically, we find an increase in the number of citywide applications in response to homicide incidents in relatively small cities and a similar response in local neighborhoods within larger cities when using measures of recent homicides at the neighborhood level. We further show that our results are robust to alternative model specifications and find similar results using alternative data sources to measure crime. Crucial to the validity of our research design, we demonstrate that the effects are present following and not prior to homicide incidents, thus reinforcing a causal interpretation of our estimates. Our estimated effects are driven by gun-related homicides and the effect is not apparent for less-serious crimes, suggesting that individual application decisions are more responsive to crimes that likely represent a more serious perceived threat. The detail of our data allow us to explore heterogeneous effects by applicant characteristics and circumstances surrounding crime incidents and to test whether applicants reacting to crime are more or less likely to renew their concealed-carry permit. We also note that homicides are infrequent and that our estimates indicate an effect only in areas close to recent homicides, which together suggest that responses to crime do not explain recent dramatic increases in concealed-carry permits in the U.S.

Our findings provide the first causal evidence linking homicide incidents - plausibly related to perceptions of crime risk - to legal gun carrying. As such, our findings contribute to a better understanding of when and why individuals choose to legally carry guns in public. 
As gun carrying has important public safety implications, our results are relevant for current and future research seeking a more comprehensive understanding of the effect of guns in society. Our analysis also adds to the literature seeking to understand the general demand for guns as concealed-carry permit applications act as a proxy for legal handgun ownership. Given the difficulty of measuring gun ownership and the lack of exogenous variation, past research has primarily relied on the General Social Survey to document important correlates of gun ownership (Glaeser and Glendon, 1998; Kleck and Kovandzic, 2009). More recently, Depetris-Chauvin (2015) uses firearm background checks and futures markets on presidential election outcomes to demonstrate an increase in background checks surrounding the 2008 election of President Barack Obama. Though concealed carry permit applications are an imprecise proxy for gun ownership, our paper is the first to directly consider the causal effect of recent crime on gun-related behaviors.

We also contribute to several areas within the literature of testing behavioral models by analyzing the prevalence of precautionary behaviors, the role of salience in application decisions, and the extent to which projection bias is present for applicants that appear to respond to recent homicide incidents. Our focus on gun-related behaviors is related to a limited literature analyzing factors contributing to private precautionary behaviors, which interact with public safety efforts and potentially deter, displace or even increase crime $\bigsqcup^{3}$ Economists have identified precautionary responses to perceived changes in crime risk including increases in homeowner purchases of alarms, locks, and bars on windows following increases in burglaries and robberies (Clotfelter, 1978; Philipson and Posner, 1996) and families moving out of neighborhoods where crime is increasing or sex offenders are identified Cullen and Levitt, 1999; Pope, 2008) 4 While survey evidence supports the notion that gun owners respond

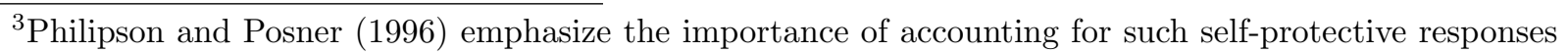
to crime as they may contribute to subsequent increases in public safety typically attributed to a public law-enforcement response to crime.

${ }^{4}$ Our research also relates to a larger literature analyzing the effect of precautionary behaviors on crime. For instance, Ours and Vollaard (2015) and Ayres and Levitt (1998) find declines in auto theft as anti-theft 
to the fear of crime, the lack of a causal link stresses the need to understand the effect of crime on gun-related precautionary behaviors ${ }^{5}$ Moreover precautionary responses that lead to increases in gun carrying have larger potential externalities than bars on windows, locks, alarms, and out-migration.

We also explore the extent to which specific factors associated with homicide incidents are systematically salient to applicant behaviors. We find that the severity of the crime and the proximity of the crime are particularly important to applicants responding to homicide incidents. Our results are consistent with recent research suggesting that individual perceptions of crime risk depend on extreme experiences with crime in the local neighborhood rather than reported aggregate crime rates (Salm and Vollaard, 2016). Furthermore, we find that the demographic salience of the homicide victim affects the responsiveness of individual applicants. For example, females are more likely to apply for a concealed-carry permit after the homicide of a female victim, but not after the homicide of a male victim 6

Finally, behavioral models suggest that consumer decisions are heavily influenced by their current mental and emotional states, which can lead to projection bias if individuals forecast future utility disproportionately based on their current state (Loewenstein et al., 2003). In our context, recent homicides may influence individuals' current state and forecasted future utility as they make decisions to apply for concealed-carry permits. Conlin et al. (2007) and Busse et al. (2015) test for projection bias by analyzing the probability of a consumerreturned purchase when purchases are likely influenced by a current emotional/mental state devices become available; Vollaard and Van Ours (2011) find declines in burglary following the installation of burglary-proof windows in newly built homes; Cook and MacDonald (2011) show that private investments in business improvement districts (BID), which include expenditures on security, significantly reduce crime in BID areas.

${ }^{5}$ A 2013 Pew survey found that 48 percent of gun owners cited protection as the main reason for gun ownership and 79 percent responded that owning/having a gun in the household makes them feel safer (Pew Research Center, 2013).

${ }^{6}$ Our finding that female applicants are not generally responsive to homicides is consistent with Braakmann (2012), who demonstrates that women are less inclined toward offensive measures in the face of increased victimization risks. 
driven by weather. Although concealed-carry permits are not returned and we do not observe if they are not used, we test for projection bias by comparing permit renewal rates of applicants who applied for a permit shortly after a proximal homicide incident to other applicants. Our results yield no evidence for projection bias, rather we find that applicants who applied for a permit shortly after a proximal homicide incident are more likely to renew their permit.

\section{Background}

Modern concealed-carry laws - establishing a permit application process - were largely implemented in the early 1990s. For instance, only ten states had concealed-carry laws in 1988, but by 1996 this number had increased to 30.7 To date, all 50 states have a concealed-carry application process, though eligibility requirements differ significantly across states 8 These laws can be broadly categorized as shall-issue, may-issue, or unrestricted carry. The majority of laws are shall-issue laws that issue concealed-carry permits to qualified applicants without stated justification for a permit. That is, as long as an individual has met the age, training, and background requirements the state shall issue a permit. In addition to considering whether the applicant meets the eligibility requirements, may issue laws require a determination of whether justification is warranted based on the stated reasons for the permit.9 More recently, several states have enacted unrestricted-carry laws that do not require a license or permit to carry a concealed weapon. As of 2015, 35 states have shall-issue laws, 9 have may-issue laws, and 6 have unrestricted-carry laws. ${ }^{10}$

A large literature explores the reduced-form effects of concealed-carry laws on crime. Lott

\begin{tabular}{l}
\hline${ }^{7}$ For additional background see Grossman and Lee $(2008)$. \\
\hline \hline${ }^{8}$ Illinois was the last state to legalize concealed carry in 2013. \\
\hline${ }^{9}$ There is significant variation in the circumstances necessary to justify a permit across may-issue states. \\
\hline \hline${ }^{10}$ Grossman and Lee $(2008)$ find that three factors increase the likelihood of adopting a shall-issue rather \\
than a may issue law including rural status, decisions of neighboring states, and increases in crime.
\end{tabular}


and Mustard (1997) were the first to show a deterrent effect of concealed-carry laws on crime, which initiated a flood of research and contentious debate on the effects of concealed-carry laws. Among those critical of Lott and Mustard (1997) include Black and Nagin (1998), Ludwig (1998), Dezhbakhsh and Rubin (1998), Duggan (2001), Ayres and Donohue (2003), and Rubin and Dezhbakhsh (2003) who find that shall-issue laws have either no significant effect on crime or slight increases in certain types of crime.11 Others have found supporting evidence for a deterrent effect of concealed carrying on crime including Lott (1998), Bronars and Lott (1998), Moody (2001), Plassmann and Tideman (2001), Olson and Maltz (2001), and Mustard (2001). We do not take a position on the consequences of these laws; rather, our focus on the determinants of concealed carrying is motivated by the many potential positive and negative externalities associated with the decision to legally carry a gun in public. Moreover, the mixed findings on this topic stress the importance of understanding behavioral mechanisms contributing to reduced-form estimates of concealed-carry laws on crime and, more generally, any estimates of the effects of gun-related policies on societal outcomes.

Though the underlying reasons for concealed carrying are typically overlooked, several studies have documented correlates of concealed-carry permits. Due to the poor quality and availability of concealed-carry data, these studies typically rely on cross-sectional comparisons of aggregate data. ${ }^{12}$ In such cases, the estimates cannot be interpreted as causal and inference regarding individual behaviors related to gun activity is severely limited. To our

\footnotetext{
${ }^{11}$ See also Durlauf et al. (2016), which discusses the role of model uncertainty in the estimating the effects of concealed carry laws on crime.

${ }^{12}$ For instance, Costanza et al. (2013) find that income, political ideology, and crime are significantly correlated with permit rates using one year of concealed-carry data in Connecticut townships. Bankston and Thompson (1989) and Costanza and Kilburn (2004) find that demographic measures and gun beliefs are correlated with concealed carrying, but show mixed results on income and crime using cross-sectional Louisiana data at the parish level. Thompson and Stidham (2010) use county-level North Carolina data aggregated to a 10-year period to estimate the correlates of concealed-carry permits and conclude that, "the important factors in explaining concealed-carry rates in North Carolina are Republicanism, annual hunting permits, and [geographic] shifts in Black population."
} 
knowledge this paper provides the first analysis exploring the causal effect of a potential determinant of gun carrying - recent crime incidents - on concealed-carry applications.

\subsection{North Carolina Shall-Issue Law}

North Carolina implemented a shall-issue law in July of 1995, joining the nationwide movement allowing qualified individuals to carry a concealed handgun in public. Prior to the law change, North Carolina statutes prohibited concealed carrying of deadly weapons outside of one's own premises. The 1995 law mandates a permit obtained through a statewide application program for any individual carrying a concealed handgun. Each applicant must be a U.S. citizen, a resident of the state for 30 days or longer, at least 21 years of age, must not suffer from a "physical or mental infirmity that prevents the safe handling of a handgun," and complete an approved course in firearm safety and training. Individuals seeking a permit must apply to the county sheriff's office and pay a non-refundable permit fee ${ }^{13}$ A permit can be denied if the individual is under indictment, has a felony record, is a fugitive from justice or is ineligible to own, possess, or receive a firearm under state or federal law. The permit is valid for five years and, unless revoked, can be renewed for consecutive five-year periods.

As highlighted by Thompson and Stidham (2010), North Carolina offers a unique setting to study behaviors leading to concealed-carry permit applications. In particular, North Carolina offers substantial variation in demographic characteristics, degrees of urbanization, income levels, educational attainment, and political ideology. The state ranks $9^{\text {th }}$ in population with nearly 10 million residents and is racially diverse, with 35 percent of the population consisting of minorities and 22 percent black. ${ }^{14}$ Historically, the state has been politically balanced and is typically labeled a swing state in presidential elections 15 Furthermore,

\footnotetext{
${ }^{13}$ The fee is $\$ 80.00$ as of 2015 .

${ }^{14}$ Based on the 2010 Population Census.

${ }^{15}$ See Thompson and Stidham (2010) for addition discussion.
} 
North Carolina's 1995 adoption of its shall-issue law provides substantial variation over time to study concealed-carry take-up.

\section{Data}

We use individual concealed-carry application information from a statewide database managed by the North Carolina State Bureau of Investigations ${ }^{16}$ The database is updated as sheriffs receive and record individual applications. Our data span 1996 to 2012, throughout which we observe over 378,000 new concealed-carry applications. The data identify each applicant's city of residence, gender, age, race, date of application and date the permit is issued 17 The data also include information on permit expirations, renewals, and whether the permit application is approved or denied.

We restrict our sample to first-time permit applicants in order to exclude individuals who renew a prior permit or submit a new application because of an expired permit. To avoid potential confounding effects due to the initial passage of the law, we also restrict the data to applications submitted after $1997 \sqrt{18}$ Figure 1 shows the number of new monthly permit applications in North Carolina from January 1998 through December 2012. The number of monthly applications remained fairly flat through the early 2000s prior to rapidly increasing in the second half of the decade. The dramatic increase in permit applications, as seen in Figure 1, is consistent with national permit trends documented by Lott et al. (2015).

We initially focus on changes in concealed-carry applications following homicide incidents, though we also consider less-serious crimes and alternative causes of external death. We measure homicides using multiple independent data sources. Our primary source is the

\footnotetext{
${ }^{16}$ Our data was obtained through a 2013 freedom of information request pursuant to North Carolina Public Records Law (G.S. 132-1 through 132-10). Please contact the authors for additional documentation.

${ }^{17}$ The median time between the application date and the issue date is 35 days.

${ }^{18}$ In results available upon request, we find that similar results are obtained when including earlier years of the data.
} 
North Carolina State Center for Health Statistics (NCSCHS) Vital Records that include all recorded deaths in North Carolina ${ }^{19}$ In these data we observe the cause of death, the city of occurrence, the date of occurrence, and the deceased individual's gender, age, race and marital status ${ }^{20}$ We use census-incorporated place identifiers in the NCSCHS to merge cities with those identified in our concealed-carry sample. As such, our analysis includes incorporated areas in North Carolina from January 1998 through December 2012 212

Our secondary source of data is the Uniform Crime Reports (UCR) collected by the Federal Bureau of Investigation (FBI). UCR data include monthly crime statistics reported by local law-enforcement agencies to the FBI. The details available in the UCR data also allow us to consider the effects of crimes, other than homicides, on concealed-carry applications. The analysis using UCR data focuses on municipal law enforcement agencies across North Carolina that are actively reporting crime data over our sample time frame.22

Although we use both the NCSCHS and UCR data in our city-level analysis, we focus primarily on the results obtained using the NCSCHS data due to several shortcomings of the UCR data. For instance, while the NCSCHS data are administrative records that include all deaths in North Carolina, the UCR is a voluntary program known to suffer from misreporting and inconsistent reporting ${ }^{23}$ Furthermore, the NCSCHS data include actual homicides rather than just homicide arrests, as observed in the UCR ${ }^{24}$ Finally, the UCR data is more difficult to match to our city-level application data as it is measured at the law enforcement

\footnotetext{
${ }^{19}$ These data were obtained from the Odom Institute (2015).

${ }^{20}$ We use the following ICD-10 codes to identify homicides: X85-X99, Y01-Y09, Y87.1. In cases where an individual died in the hospital, the city of residence is used rather than city of occurrence.

${ }^{21}$ The Census designates incorporated areas if the population exceeds 2,500.

${ }^{22}$ To avoid problems with inconsistent or incomplete reporting in the UCR, we (i) visually inspect the data for lumpy reporting (e.g. quarterly/yearly reporting instead of monthly reporting or disproportionate reporting at the end of the year) and (ii) keep agencies that report in 95 percent of months since being first observed in out sample.

${ }^{23}$ See for example Maltz $(2010)$.

${ }^{24}$ In addition to unjustified criminal homicides, the NCSCHS includes justified homicides, which potentially affect decisions to apply for concealed-carry permits. According to 2013 UCR, 94 percent of homicides are unjustified criminal homicides.
} 
agency level and municipal agency jurisdictions are not necessarily defined by city boundaries. The NCSCHS data, on the other hand, allow for a direct city-level match with our application data.

As the NCSCHS data are at the city-by-month level, we aggregate our application data similarly to obtain a city-by-month panel of concealed-carry permits and mortality outcomes. Our sample is a balanced panel of 30,780 city-by-month observations from 171 cities 25 Column 1 of Table 1 shows monthly summary statistics for these data. In Columns 2 and 3 we also show summary statistics by city population as we anticipate differential responses to crime across small and large cities. In particular, homicides in relatively small cities may be more likely to affect average perceptions regarding crime risk and subsequent changes in concealed-carry applications. That is, homicides in relatively small cities are far less frequent and more "local" in terms of proximity. Alternatively, homicides in relatively large cities occur more frequently and a relatively small fraction of the city population is likely to perceive a change in risk related to crime.

Based on the 2010 annual population of each city, there are 86 cities at or below the median population of approximately 8,500. Although the average population is roughly 10 times smaller in cities below the median than above the median, the mean number of applications is only roughly four times smaller in cities below the median. This is further reflected by an application rate nearly twice as large in relatively small cities. In Panel A of Table 1, we show the means for all dependent variables used in our analysis. Across small and large cities, average monthly applications are relatively high for males and whites.

In Panel B of Table 1 we show summary statistics for the NCSCHS homicide measures used in our analysis. Though we demonstrate similar results using alternative approaches to measure homicides, we initially focus on normalized homicides. Specifically, for a given

\footnotetext{
${ }^{25}$ Our main analysis uses a non-linear maximum likelihood estimator that includes city-by-year fixed effects. As such, 600 of the 30,780 matched observations that are used in the analysis are dropped as some of the city-by-month observations have no variation in applications with a given year.
} 
city and month we calculate normalized homicides by subtracting the mean homicides from the previous 36 months and dividing by the standard deviation over the 36 month period. Observations that do not observe a homicide in the previous 36 months take the value of zero. Column 1 indicates that 11 percent of all cities experience a homicide in the average month and that there are 0.181 homicides per city-month. Not surprisingly, large cities are more likely to have a homicide in any given month, though the homicide rates are similar across large and small cities. Notably, 97 percent of monthly homicides in small cities are single homicide incidents, while the same is true for 65 percent of monthly homicides in cities above the median population. Lastly, across both small and large cities approximately two-thirds of homicides are committed with a gun.

\section{Empirical Strategy}

As discussed previously, we initially focus on the response of new concealed-carry applications to homicide incidents and later extend the analysis to other crimes. Given our focus on the number of concealed-carry applications and because we often have cells with zero applications, our estimates are based on Poisson models, which have several advantages over alternative count models such as a negative binomial. For instance, Poisson models avoid incidental parameters problems when including fixed effects and do not require the arrival process for the number of applications to follow a Poisson distribution. Rather, the consistency of the time-varying covariates simply depends on correct specification of the conditional mean of the outcome (Cameron and Trivedi, 1986). Furthermore, we relax the assumption of equality between the conditional mean and variance by calculating robust standard errors (Wooldridge, 1997; Cameron and Trivedi, 2013).

Our empirical approach exploits variation in homicide incidents within cities over time

to identify the effect of crime on new concealed-carry permit applications. In our baseline 
model we assume that the number of applications, App, in city $i$, year $y$, and month $m$, is characterized by

$$
A p p_{i, y m}=\exp \left(\sum_{j=1}^{n} \beta_{j} \text { homicide }_{i, y m-j}+\gamma_{i}+\alpha_{y}+\theta_{m}+\varepsilon_{i, y m}\right),
$$

where homicide $_{i, y m-j}$ are lagged normalized homicides over a 36-month recall window at year and month $y m-j, \gamma_{i}$ are city fixed effects, $\alpha_{y}$ are year fixed effects, $\theta_{m}$ are month fixed effects, and $\varepsilon_{i, c, t}$ is an unobserved error term. We calculate standard errors corrected for potential clustering at the city level to address the possibility that monthly observations within cities are correlated.

The inclusion of city fixed effects ensures that the estimated effects are driven by within city variation over time rather than variation across cities. This is important as timeinvariant city characteristics are likely related to crime rates and the number of concealedcarry permits. Our baseline model also controls for year and month effects, which account for aggregate annual shocks and seasonality in the demand for concealed-carry permits.

We expand upon the baseline model, as represented in Equation 1, by further including city-by-year fixed effects and county-specific linear trends. City-by-year fixed effects additionally control for city-year specific shocks affecting concealed-carry permit applications such as annual changes in crime levels, population, demographic composition, policing, and other relevant city, county, or state shocks and policy changes. Including county-specific linear trends accounts for the possibility that homicides are correlated with trends in applications within areas. Finally in a robustness exercise we show estimates using models that also include year-by-month fixed effects and city-specific linear trends.

Our use of lagged normalized homicides in Equation 11 implicitly assumes that recent homicides affect current application decisions and allows us to test the persistence of the effect. We also explore models including leads to address concerns regarding reverse causality. 
The results of this analysis, discussed in more detail below, reveal that monthly changes in homicides are not driven by recent changes in concealed-carry applications.

Our motivation for initially focusing on a normalized measure of homicides is two-fold. First, the normalized measure further parses out city-specific effects by capturing deviations from recent norms. Although we control for city-by-year fixed effects, using normalized homicides over a 36-month recall allows us to exploit changes from recent past homicides rather than relying on deviations from past and future homicides within city-years. Second, a measure of normalized homicides is continuous and therefore allows for variation on intensive margins not captured by a dichotomous variable. That said, our results are similar using alternative measures of homicides such as levels, rates, a dichotomous monthly indicator, and normalization measures that use shorter or longer recall windows.

Intuitively, our preferred specification compares the number of applications within cityyears following changes in previous-month homicide incidents, while controlling for the differences that are expected across months of the year and county-specific linear trends in applications. Under the assumption that other determinants of concealed-carry permits are unrelated to the timing of local homicide incidents across months within city-years and after adjusting for seasonality, the estimate of $\beta$ identifies the causal effect of a one-standard deviation in a previous month homicide on the number of new concealed-carry applications. Though we start by showing estimates for all cities in our sample, our main analysis by city size leads us to focus exclusively on concealed-carry applications within relatively small geographic areas over time. In a subsequent section we further explore the influence of geographical proximity to crime on concealed-carry applications in an ancillary analysis that uses disaggregated crime data in several relatively large cities in North Carolina. 


\section{Results}

\subsection{Main Results}

Panel A of Table 2 shows the estimated effects of lagged homicides on concealed-carry applications for all 171 cities in our sample. Columns 1-3 report the estimates from increasingly flexible specifications starting with a model that includes city, year, and month fixed effects. Column 2 adds city-by-year fixed effects and Column 3 adds county-specific linear trends. Panels B and $\mathrm{C}$ focus specifically on estimates for the cities below and above the median population, respectively.

The results using the full sample of cities (Panel A) suggest that homicides have no significant effect on concealed-carry permit applications. This is not surprising given that many of these cities are large urban areas where homicides are relatively frequent and are less "local" in the sense that neighborhoods directly affected by the incident are likely only a small fraction of the city-wide population. Indeed, stratifying the estimates by median population reveals that the Panel A estimates mask important differences across city size. In particular, the results in Panel B suggest that in cities below the median population, a one standard deviation increase in homicides in the previous month increases the application rate by approximately 2.5 percent and a similar increase in homicides two months prior increases the application rate by approximately 2.2 percent (Column 3) 26 On the other hand, the estimates in Panel $\mathrm{C}$ indicate no effect of homicides on permit applications in larger cities. ${ }^{27}$ While the results in Table 2 provide evidence that applications respond in areas relatively near the homicide incident, we note that there may also be other differences between large and small cities with regards to concealed carrying.

Given that one homicide represents 5.55 standard deviations from the mean, our results

\footnotetext{
${ }^{26}$ More precise and slightly larger percentage effects can be calculated as $\left(e^{\beta}-1\right)$.

${ }^{27}$ Limiting the data to cities that have a population in the bottom tercile results in point estimates that are slightly larger than the estimates reported in Column B.
} 
in Panel B Column 3 suggest that one additional homicide in a given month increases applications by 26 percent over the next two months in cities below the median population ${ }^{28}$ Although the estimates demonstrate a large response to a local homicide incident, it is also worth noting that given the infrequency of homicides within these cities, homicides explain only a small portion of the variation in the number of applications.

\subsection{Sensitivity Checks}

Focusing specifically on the sample of cities below the median population, we next consider whether our estimates are sensitive to alternative specifications and measures of homicides. Panel A of Table 3 shows specifications that more flexibly control for any year-month-specific shocks and city-specific time trends. For comparison, Column 1 of Panel A first reports the estimates from Column 3 of Table 2 Panel B. Column 2 adds year-by-month fixed effects and Column 3 additionally controls for city-specific linear time trends. Notably, the estimates across the specifications in Panel A are similar in magnitude and precision suggesting that our estimates based on Equation 1 are not sensitive to additional controls for year-month shocks and city-specific trends.

In Panel $\mathrm{B}$ of Table 3 we measure homicides using monthly homicide indicator variables instead of normalized homicides. These results provide a similar narrative to those presented in Panel A. Particularly, a homicide incident in the previous month increases applications by approximately 10.3 percent and a homicide two months prior increases applications by approximately 11.8 percent (Column 1) in cities with below median population. The results indicate that a recent homicide increases applications by 22.1 percent (by 10.3 percent next month and by 11.8 percent the following month), or by roughly two-thirds of an application. The results that use an indicator variable for homicide incidents demonstrate a similar effect on concealed-carry applications as the results in Panel B of Table 2. As such, and given the

\footnotetext{
${ }^{28}$ One standard deviation in homicides is 0.18 . The percentage effect is $5.55 \times 2.5 \%+5.55 \times 2.2 \%=26 \%$.
} 
ease of interpreting the coefficient estimates our subsequent analysis focus on estimates using monthly homicide indicator variables ${ }^{29}$ As the estimates in Table 3 reveal no meaningful differences across specifications (Columns 1-3), our subsequent results continue to focus on the specification reported in Column 1, which includes month fixed effects, city-by-year fixed effects, and county specific time trends 30

\subsection{Additional Estimates by City Size}

To further investigate the role of city size, we next explore how the estimates change when we focus on alternative stratifications of smaller and larger populated cities. Specifically, we use a moving sample size of 40 cities, starting with the 40 least populated cities and incrementally move to a sample of the 40 most populated cities, plotting each coefficient estimate. We continue to employ a similar specification as in Column 3 of Table 2, with the exception that our measure of homicides is an indicator variable taking a value of one if there was a homicide in the previous two months. This process results in 132 estimates, which we plot in Figure 2. The point estimate for the 40 smallest cities is shown on the furthest left point of the graph (approximately 0.14). As seen in the figure, estimates in cities below the median are consistently positive, but incorporating variation from larger cities leads to point estimates close to zero and not statistically different from zero, reinforcing the finding that the effect is more salient in smaller, more localized settings. ${ }^{31}$ Given these results, our next set of tables focuses on cities below the median population, though in subsequent analysis we also consider the effects in several large cities in North Carolina using alternative disaggregated crime data.

\footnotetext{
${ }^{29}$ In Appendix Table $\mathrm{A} 2$ we show similar estimates using either homicides levels or rates.

${ }^{30}$ Our primary motivation for using the more parsimonious specification is to help facilitate convergence of the estimates in subsequent heterogeneity analyses.

${ }^{31}$ The figure is very similar when we use the marginal effect from normalized homicides last month and the month prior, as shown in Appendix Figure 1
} 


\subsection{Treatment-Effect Dynamics}

In this section, we explore estimates from models with additional lag and lead homicide indicator variables in order to consider the dynamic effects of homicides on concealed-carry applications. In addition to providing insight into the persistence of the effect, this analysis serves to address concerns that changes in the number of homicides may be driven by recent changes in concealed carrying and/or related activities. That is, this approach allows us to address potential concerns over the causal direction of the estimates and to capture the temporal relationship between permit applications and homicides.

Column 1 of Table 4 shows estimates from a model including separate indicator variables for homicides one, two, and three months prior, in order to explore the lagged effects of homicides on concealed-carry applications. In columns 2 through 7 we sequentially add indicator variables for homicides in the current month, next month, ..., in four months, and in five months. This provides 21 "placebo tests" across these 6 columns where we do not anticipate any systematic effects.

The results in Table 4 demonstrate that homicides in the month prior and two-months prior significantly increase concealed-carry applications. The results across columns 2 through 7 also suggest that current permit applications are not be systematically related to homicides in future months. We view this as strong evidence supporting our identification strategy and reinforcing a causal interpretation of our results. As these estimates suggest a two-month lagged effect of homicides on applications, the remainder of our analysis primarily focuses on models that include an indicator for a homicide in the previous two months.

\subsection{Gun-Related Homicides and Other Causes of Death}

Thus far we have shown evidence that the number of concealed-carry applications in relatively small cities respond to homicide incidents, consistent with the notion that more proximal 
perceived threats affect individual gun-related decisions. If individuals are also sensitive to the severity of perceived threats, we may expect a more pronounced response following homicides committed with a gun and we would not expect a response to alternative causes of external death where the perceived threat is likely minimal or nonexistent. In Table 5 we show estimated effects by gun and non-gun related homicides and alternative causes of external death available in the NCSCHS data. We are particularly interested in the degree to which homicides with a gun differentially affect the decision to apply for a concealed handgun permit, as shown in Column 2. The estimates reveal that the estimated effect of all homicides is largely driven by gun-related homicides ${ }^{32}$

In columns 4-6 of Table 5 we assess whether other external causes of death that are less likely to influence perceived security affect permit applications. We focus on the three most commonly observed external causes of death: motor vehicle accidents, suicides, and drug-overdoses 33 The bottom row in the table shows the mean monthly mortality rate for the cities below the median population in in our data. The estimated effects of external causes are small relative to the estimated effect of a recent homicide and are not statistically significant, suggesting that these other common causes of death do not increase permit applications.

\subsection{Heterogeneity by Applicant Characteristics}

To explore whether applications from particular individuals are more responsive to recent crime, we next estimate models including demographic-specific application counts. As reported in Table 1, whites and males have much higher baseline application counts in cities below the median population. Table 6 presents the estimated effects of a homicide in the previous two months on the number of applications across demographic groups. For compar-

\footnotetext{
${ }^{32}$ In the data, approximately two-thirds of homicides in North Carolina are gun-related.

${ }^{33}$ Drug-overdoses consist of deaths from accidental poisoning and exposure to noxious substances.
} 
ison, Column 1 presents the estimated effect for all individuals, and estimates by race, gender and age categories are shown in columns 2 through 8 . The results suggest that whites, males, and persons that are of ages 40-59 are most responsive, with the point estimates suggesting a 13 to 14 percent increase in applications following a homicide in the previous two months (i.e. a homicide increases applications by 26 to 28 percent over the next two months). The estimate on females, ages 21-39 and ages 60+ are positive, but imprecise, while the estimated effect on black applications suggests no response.

Our previous results demonstrate that gun-related homicides and homicides in relatively small cities are more salient to permit application decisions. However, spatial distance is just one dimension that may influence an individual's decision to apply for a permit. It may also be the case that sharing common characteristics with the homicide victim influences the perceived likelihood of victimization and subsequent decisions toward self-protection. Existing research provides related evidence suggesting that individual behaviors change as beliefs are updated based on experiences of others in comparable situations. For example, Lochner (2007) finds that perceived probabilities of arrest are related to a sibling's criminal history and avoidance of arrest. In the context of health behaviors, Lin and Sloan (2015) find that smokers are more likely to quit smoking when a nearby resident is diagnosed with lung cancer. Along these lines, we next test whether the salience of the victim influences potential applicants. In other words, are applications more responsive when the applicant shares a common characteristic with the victim?

To analyze the extent to which victim salience contributes to changes in applications we estimate a model similar to Equation 1 that focuses on incidents where applicants and homicide victims within the same city are of a similar demographic. For instance, for females we estimate the following Poisson regression model,

$$
F e m A p p_{i, y m}=\exp \left(\beta_{1} F e m V i c_{i, y m}+\beta_{2} \text { OthVici,ym }+\alpha_{m}+\gamma_{i, y}+\operatorname{Trend}_{y m} \lambda_{c}+\varepsilon_{i, c, y m}\right),
$$


where FemApp $p_{i, y m}$ is the number of female permit applications in city $i$, year $y$, and month m. FemVic $c_{i, y m}$ is an indicator that takes the value of one if there was a homicide in the previous two months and the victim was a female. Similarly, OthVic $c_{i, y m}$ is an indicator that takes the value of one if there was homicide in the previous two months and the victim was not a female. $\alpha_{m}$ and $\gamma_{i, y}$ represent month fixed effects and city-by-year fixed effects, and Trend $d_{y m} \lambda_{c}$ represent the inclusion of county specific linear time trends.

The results of this analysis are reported in Table 7. Columns 1 through 8 indicate the demographic-specific measure of concealed-carry applications and each row corresponds with the demographic-specific homicide indicator variables included in the model. Prior to inspection of the results, it is worth noting that the estimates of $\beta_{1}$ and $\beta_{2}$ presented in columns 1 through 4 of Table 7 are simply a weighted average of the point estimates presented in columns 2 through 5 of Table 6 where the weighting is determined by the share of victim homicides within each demographic group. We also note that the fluctuation in our sample size across columns 1 through 8 is a result of using a fixed-effects maximum likelihood approach which drops observations lacking variation in demographic-specific applications within city-years.

The results in Table 7 provide evidence for a more pronounced effect on applications in cases where the applicant and the victim share a similar demographic characteristic. In particular, the point estimates for males, females, black males, black females, and white females reveal a relatively large response when the victim shares similar demographic characteristics, though several of the estimates are very imprecise. The effects on female applicants shown in Column 4 are particularly notable, revealing that potential female applicants are not sensitive to non-female homicide incidents, but increase applications by approximately 26 percent if the victim of a homicide in the last two months is a female. Otherwise stated, concealed-carry permit applications by females increase by approximately 52 percent over the next two months when a homicide victim is a female. Though the estimates are noisy 
and should be interpreted with caution, the same pattern emerges for black and white female applicants shown in columns 7 and 8. The estimates in columns 2 and 6 do not reveal a similar pattern for aggregate white applicants and white male applicants. Taken together, the estimates in Table 7 provide evidence that, at least for females, the response is more pronounced when the victim is also a female.

\subsection{Estimated Effects on Permit Renewals}

In this section, we explore the extent to which recent homicides also affect the likelihood of a permit renewal. Doing so allows us to speak to longer run decisions to extend the option to legally carry a concealed firearm. It is not clear a priori how homicides might affect the likelihood of renewal. On one hand, we might expect applicants responding to recent homicides to experience a temporary emotional response to a perceived threat or an overreaction. In this case we would expect such applications to have a lower likelihood of renewal. On the other hand, nearby homicide incidents may have longer-term effects on individuals and increase the likelihood of renewal relative to alternative motivations for permit applications.

Our analysis on permit renewals is related to recent empirical research testing for systematic projection bias in individual-decision making. In contrast to standard assumptions that individual forecasts of future utility are, on average, equal to realized utility, recent research has shown that individuals may be systematically biased when predicting future utility. To illustrate evidence of projection bias, Busse et al. (2015) show that contemporaneous weather influences new four-wheel drive and convertible purchases, but that weather-influenced vehicle purchases are more likely to be returned. Conlin et al. (2007) find similar evidence in catalog ordering by showing that decisions to purchase cold-weather items are influenced by weather at the time of purchase, and that these items are more likely to be returned. Similarly, we test for projection bias by comparing permit renewal rates of applicants who 
applied for a permit following a recent homicide to other applicants.

For this analysis we focus on the first-time permits in cities below the median population that expired at least a year before the end of our data (2012) ${ }^{34}$ Of these, 69 percent renewed within six months of the expiration. We test for differences in renewal rates using a linear probability model where the outcome takes the value of one if the permit was renewed within six months of the expiration date, and zero otherwise ${ }^{35}$

Table 8 reports the estimated effects of a homicide within the past two months on the probability of a renewal within six months of the expiration date. In columns 1 and 2 we show results using all homicides and gun-related homicides. While there is no apparent response to all homicides in Column 1, Column 2 suggests that a recent gun-related homicide increases the probability of renewal by 5 percentage points, representing a 7 percent increase over the baseline renewal rate. In columns 3 through 9 we show the effects of gun-related homicides by applicant demographic characteristics. Similar to Table 6, we find that the effects are driven by whites and males. Columns 7 through 9 indicate that the effect on renewals is more pronounced among individuals over the age of 40. Taken together, our results yield no evidence for projection bias, rather they suggest that applicants who applied for a permit shortly after a homicide incident are more likely to renew their permit.

\subsection{Estimated Response to Other Crimes}

Consistent with previous research documenting increases in personal protection measures following higher crime rates, our results reveal an increase in concealed-carry permit applications following homicide incidents. We next explore whether this is also true for less serious types of crime that may be less likely to influence perceptions of personal security. As discussed in the data section, we use municipal law-enforcement agency crime reports

\footnotetext{
${ }^{34}$ Similar to our main analysis, we find that homicides do not affect permit renewals in larger cities.

${ }^{35} \mathrm{In}$ results available on request, we find similar estimates if using indicators for a renewal within 3 and 12 months of the expiration date, respectively.
} 
available in the UCR data ${ }^{36}$ Of the 171 in our NCSHS data, 132 cities are represented by a municipal law enforcement agency in the UCR data, while 69 of the 132 cities are part of the subset cities below the median population. The difference in the number cities between the two samples is related to the limited number of agencies in the UCR as well as the NCSCHS only including incorporated census areas. Prior to exploring other crime incidents, we explore whether the matched cities in the NCSCHS data and the UCR data present similar estimates.

Table 9 presents the effects of homicide incidents this month and two months prior on concealed-carry applications using the UCR matched application data. Similarly to our results using the NCSCHS data, we continue to find that homicide incidents in the previous two months increase the number of concealed-carry applications in the subset of cities below the median population, but not for cities above the median. For cities below the median population (Column 2), the size of the point estimates are comparable to those presented in tables 2 and 3 , but suggest an even larger effect of a homicide incident in the previous month. For the cities above the median, the estimates are small in magnitude and not statistically distinguishable from zero ${ }^{37}$ In addition, we also estimate the dynamic specification including additional leads and lags using the UCR data. Similar to the results in Table 4 , we find that homicide incidents in the the previous two months increase concealed-carry applications and that homicide incidents in future months are not related to current applications (Appendix Table A5). While the estimates across these two data sources are similar, one difference is a positive and significant contemporaneous effect when using UCR data that is not apparent

\footnotetext{
${ }^{36}$ We also considered estimates using the UCR Homicide Supplement, which contains additional detail on each homicide incident including relationships between the victim and offender. Unfortunately, the majority of below-median population agencies do not report consistently to the homicide supplement, resulting in a small sample size, far fewer homicides, and imprecise estimates. Notably, of the homicides that are reported homicide supplement, only 4 percent are homicides that are perpetrated by family members.

${ }^{37}$ To further explore if the matched cities in the NCSCHS data and the UCR data present similar estimates, we restricted the NCSCHS data to the same city observations as the UCR data and found similar estimates to those presented in Table 9 (see Appendix Table A4).
} 
when using NCSHS data. This difference is likely due to the fact that the NCSCHS data measure the precise timing of homicide incidents, while the UCR data measure arrests. If arrests are occur following the initial homicide incident, we might expect the observed differences in estimates using NCSCHS and UCR data as individuals likely respond to the incident rather than the arrest.

Table 10 presents estimates of the effect of crime on permit applications by property and violent crimes. Columns 1 through 5 focus on violent crimes including homicide, rape, aggravated assault, and robbery, while columns 6 through 9 focus on property crimes including burglary, larceny, and motor vehicle theft. In addition to showing the estimates using the indicator variable for a crime in the previous two-months (Panel A), we also show the estimates using lagged normalized crimes in Panel B. Our inclusion of estimates based on normalized crimes is due to the limited variation in the two-month indicator variable for aggregated and frequently occurring crimes. For instance, the probability of observing at least one crime in the previous two months - shown in the bottom row in Panel A - is 79 percent for all violent crimes and 97 percent for all property crimes.

The estimates shown in Table 10 panels A and B suggest that individual permit applications are not responsive to violent or property crimes, with the exception of homicides. Other than a marginally significant estimate on the one-month lag of normalized larceny, none of the non-homicide crime estimates are significant and all are small in magnitude relative to the effect following a homicide incident ${ }^{38}$ That applications appear to respond to recent homicides, but not other crimes, reinforces the notion that application decisions are only sensitive to serious perceived threats. It may also be the case that the general public is more aware of homicide incidents as they may be publicized to a greater degree than other crime incidents, especially in small communities.

\footnotetext{
${ }^{38}$ In results available upon request, we further explore the effect of on gender-specific applications, but find no significant effects.
} 


\section{Ancillary Analysis Using Disaggregated Data}

Our previous estimates demonstrate robust effects of homicide incidents on concealed-carry permits, but only in relatively small cities. We view this as suggestive evidence that the proximity of the homicide incident - as measured by city size - is a likely factor influencing decisions to apply for concealed-carry permits. To test this further, we estimate the effect using disaggregated data in several large cities to determine if homicide incidents and other types of crime influence concealed-carry applications within local neighborhoods.

Our crime data for this analysis come from SpotCrime, a prominent crime data aggregator that gathers detailed information on crime incidents including a description of the incident, address, geotag, type, date, and time. The data are collected primarily from police departments, but are also augmented by news reports and user input. SpotCrime provided these data for reporting cities in North Carolina from 2008-2010 ${ }^{39}$ A close look at the data reveals that reporting over these years is limited or irregular for many cities. We focus on the three cities that report consistently for a significant share of the sample. These three cities are also three of the five largest cities in North Carolina. Specifically, we use data from Charlotte (April 2009 - July 2010), Raleigh (August 2008 - December 2010), and WinstonSalem (June 2008 - December 2010) ${ }^{40}$ Notably, these three cities account for approximately 15 percent of North Carolina's 10 million residents.

SpotCrime data report common categories of crime including arrest, arson, assault, burglary, robbery, shooting, theft, vandalism, and other crimes. In addition, the crime observations contain a general description of each crime incident such as "larceny auto accessories", "breaking and entering felony/non-forced", and "drug violation". For more serious and less

\footnotetext{
${ }^{39}$ Unfortunately, SpotCrime does not provide data pre 2008 or post 2010.

${ }^{40}$ These three cities accounted for 68 percent of the crime incidents in the data we received from SpotCrime. Charlotte, Raleigh, and Winston-Salem had 68,758, 39,722, and 45,301 crime incidents, respectfully. Durham, the city with the next most number of crime incidents in our data had 21,168 crime incidents. Most notably, Durham and other relatively population dense cities did not have consistent crime incident reporting and were thus excluded from the analysis.
} 
common incidents, the description often includes a detailed account of the crime. Using the categories and descriptions of each incident, we identify and focus on six types of crime: homicide, assault, burglary, robbery, theft, and vandalism 41 Similar to our main analysis, our initial focus is on homicides. We observe 100 homicides and 8,317 concealed-carry applications in Charlotte, Raleigh, and Winston-Salem during our sample time period 42

As we are interested in the extent of which proximity to the homicide effects concealedcarry applications, we present results from several levels of aggregation. Census sub-city geographic entities provide a natural breakdown for this exercise as they are defined by criteria including a "homogeneity principle" that defines areas based on "a nucleus with its surrounding zone of influence" (US Census Bureau, 2012). In particular we show estimates using census tracts, block groups, and blocks 43 Census tracts, block groups, and blocks are geographic areas defined by visible features (e.g. streets roads, highways, rivers, railroads etc.) and with specified population and geographical criteria (US Census Bureau, 2012).

Descriptive statistics of the SpotCrime data merged with concealed-carry application data are reported in Appendix Table A6. The average population in census tracts, block groups, and blocks is $1,556.8,765.3$, and 204.7, respectively. In these cities, we observe an application rate of approximately 8.8 per 10,000 individuals, notably higher than the 5.3 applications per 10,000 that we observe using all the cities in the NCSCHS sample ${ }_{44}^{44}$ This is largely due to much higher application counts in these years as can be seen in Figure 1

Following the identification strategy outlined in Section 4, we estimate the effect of a crime incident in the previous two months on applications for concealed-carry permits within

\footnotetext{
${ }^{41}$ Though homicide is not a distinctly identified category, the detailed descriptions allowed us to identify situations where a murder or homicide took place.

${ }^{42}$ Using the same sample of city-months, NCSHS data suggest a total of 158 homicides suggesting that SpotCrime data may understate the actual number of homicides.

${ }^{43}$ The analysis further aggregated to the city or county level yield no significant effects of homicides on concealed-carry applications.

${ }^{44}$ We also observe a higher homicide rate in the SpotCrime data. Specifically, at the block level we observe 0.00217 homicides per 203.7 individuals. This implies a homicide rate of 0.106 per 10,000 individuals. This is noticeably larger than the rate of 0.066 per 10,000 individuals as observed in the NCSCHS data.
} 
census areas. Similar to our main specification, our analysis controls for month fixed effects, area-by-year fixed effects, and city-specific linear time trends. We calculate standard errors corrected for potential clustering at the geographic level of aggregation.

\subsection{Ancillary Analysis Results}

Table 11 shows the effect of a homicide incident on concealed-carry applications when analyzed at the census tract, block group, and block level. Although we find no evidence that a homicide incident in the previous two months leads to an increase in concealed-carry applications in census tracts or block groups, the estimates within census blocks suggest that a homicide incident in the previous two months increases the number of concealed-carry applications by approximately 27 percent. In other words, a homicide incident increases applications by approximately 54 percent over the next two months.

We next estimate the effect of other types of crime on concealed-carry applications at the city block level. Table 12 reports the estimated effects following homicides, assault, burglary, robbery, theft, and vandalism. Similar to our findings in Table 10, the estimated effects of other crimes shown in columns 2 through 6 suggest no meaningful impact on concealedcarry applications, though the effect of an assault is marginally significant. Notably the magnitudes of the point estimates on other crimes are small relative to the estimated effect of homicides. Taken together, the estimates using city block level data support our main findings that applications are responsive to more serious perceived threats as measured by recent local homicide incidents. In appendix tables A7 and A8 we show dynamic estimates and estimates across applicant characteristics. Similar to tables 4 and 6 , these results reveal reveal no relationship between current applications and subsequent homicides and continue to show that the effect is largely driven by male applicants. 


\section{Conclusion}

Using data on all concealed-carry permit applications in North Carolina from 1998 to 2012, we exploit variation in recent crime incidents to estimate the effect of crime on concealedcarry applications. We find that recent homicide incidents increase individual applications in relatively small cities and in larger cities within census block neighborhoods. Our citylevel estimates indicate that an additional homicide incident increases applications by 26 percent over the following two months in relatively small communities (cities with belowmedian population). The city-level estimates diminish when analyzing larger cites (Figure 2), though analysis using disaggregated data reveals relatively large effects in neighborhoods within relatively large cities. An additional homicide increases applications by 54 percent over the next two months within census block neighborhoods in large cities. Taken together, we view this as evidence that proximity to recent serious crime plays an important role as individuals make decisions regarding legal gun carrying.

The details available in our data also allow us to provide insight into specific circumstances surrounding homicide incidents and characteristics of responsive applicants. We find that gun-related homicides drive our main estimates and that whites and males are generally most responsive to homicide incidents. Our results suggest that applicants respond more when the homicide victim is the same gender or race, particularly for female applicants. Finally, we find that individuals responding to recent gun homicide incidents are more likely to renew their permits upon expiration relative to other applicants.

Our results provide the first causal evidence linking recent crime to applications for concealed-carry permits. We view our research as taking an initial step toward a better understanding of the determinants of concealed carrying and contributing to a more informed debate regarding the interaction between legal gun ownership, public safety and trade-offs associated with public and private security efforts. Given the recent dramatic increase in 
the number of concealed-carry permits and ongoing gun control debates, understanding the determinants of concealed-carrying and the demand for guns remains an important area for future research. 


\section{References}

Ayres, I. and J. J. Donohue (2003). Shooting down the "more guns, less crime" hypothesis. Stanford Law Review 55(4), pp. 1193-1312.

Ayres, I. and S. D. Levitt (1998). Measuring positive externalities from unobservable victim precaution: An empirical analysis of lojack. The Quarterly Journal of Economics 113(1), $43-77$.

Bankston, W. B. and C. Y. Thompson (1989). Carrying firearms for protection: A causal model*. Sociological Inquiry 59(1), 75-87.

Black, D. A. and D. S. Nagin (1998). Do righttocarry laws deter violent crime? The Journal of Legal Studies 27(1), pp. 209-219.

Braakmann, N. (2012). How do individuals deal with victimization and victimization risk? longitudinal evidence from mexico. Journal of Economic Behavior $\&$ Organization $84(1)$, $335-344$.

Bronars, S. G. and J. Lott (1998). Criminal deterrence, geographic spillovers, and the right to carry concealed handguns. The American Economic Review 88(2), pp. 475-479.

Busse, M. R., D. G. Pope, J. C. Pope, and J. Silva-Risso (2015). The psychological effect of weather on car purchases. The Quarterly Journal of Economics 130(1), 371-414.

Cameron, A. C. and P. K. Trivedi (1986). Econometric models based on count data. comparisons and applications of some estimators and tests. Journal of applied econometrics 1(1), $29-53$.

Cameron, A. C. and P. K. Trivedi (2013). Regression analysis of count data, Volume 53. Cambridge university press. 
Clotfelter, C. T. (1978). Private security and the public safety. Journal of urban economics 5(3), 388-402.

Conlin, M., T. O'Donoghue, and T. J. Vogelsang (2007). Projection bias in catalog orders. The American Economic Review 97(4), 1217-1249.

Cook, P. J. and J. MacDonald (2011). Public safety through private action: an economic assessment of bids*. The Economic Journal 121 (552), 445-462.

Costanza, S., J. Kilburn, and B. Miles (2013). The spatial dynamics of legal handgun concealment. Crime Mapping: A Journal of Research and Practice 5(1), 39-62.

Costanza, S. E. and J. C. Kilburn (2004). Circling the welcome wagons: Area, income, race, and legal handgun concealment. Criminal Justice Review 29(2), 289-303.

Cullen, J. B. and S. D. Levitt (1999). Crime, urban flight, and the consequences for cities. Review of economics and statistics 81(2), 159-169.

Depetris-Chauvin, E. (2015). Fear of obama: An empirical study of the demand for guns and the us 2008 presidential election. Journal of Public Economics 130, 66-79.

Dezhbakhsh, H. and P. H. Rubin (1998). Lives saved or lives lost? the effects of concealedhandgun laws on crime. The American Economic Review 88(2), pp. 468-474.

Duggan, M. (2001). More guns, more crime. The Journal of Political Economy 109(5), $1086-1114$.

Durlauf, S. N., S. Navarro, and D. A. Rivers (2016). Model uncertainty and the effect of shall-issue right-to-carry laws on crime. European Economic Review 81, 32-67.

Glaeser, E. L. and S. Glendon (1998). Who owns guns? criminals, victims, and the culture of violence. American Economic Review, 458-462. 
Grossman, R. S. and S. A. Lee (2008). May issue versus shall issue: Explaining the pattern of concealed-carry handgun laws, 1960-2001. Contemporary Economic Policy 26(2), 198206.

Kleck, G. and T. Kovandzic (2009). City-level characteristics and individual handgun ownership effects of collective security and homicide. Journal of contemporary criminal justice 25(1), 45-66.

Lin, W. and F. Sloan (2015). Risk perceptions and smoking decisions of adult chinese men. Journal of health economics 39, 60-73.

Lochner, L. (2007). Individual perceptions of the criminal justice system. American Economic Review 97(1), 444-460.

Loewenstein, G., T. O’Donoghue, and M. Rabin (2003). Projection bias in predicting future utility. The Quarterly Journal of Economics, 1209-1248.

Lott, J. (1998). The concealedhandgun debate. The Journal of Legal Studies 27(1), pp. 221-243.

Lott, J. and D. B. Mustard (1997). Crime, deterrence, and righttocarry concealed handguns. The Journal of Legal Studies 26(1), pp. 1-68.

Lott, J., J. E. Whitley, and R. C. Riley (2015). Concealed carry permit holders across the united states. Technical report, Crime Prevention Research Center, http://crimepreventionresearchcenter.org/wp-content/uploads/2015/07/2015-Reportfrom-the-Crime-Prevention-Research-Center-Final.pdf.

Ludwig, J. (1998). Concealed-gun-carrying laws and violent crime: evidence from state panel data. International Review of Law and Economics 18(3), 239-254.

Ludwig, J. (2000). Gun self-defense and deterrence. Crime and Justice 27, pp. 363-417. 
Maltz, M. D. (2010). Look before you analyze: Visualizing data in criminal justice. In Handbook of quantitative criminology, pp. 25-52. Springer.

Moody, C. E. (2001). Testing for the effects of concealed weapons laws: Specification errors and robustness. Journal of Law and Economics 44(S2), pp. 799-813.

Mustard, D. B. (2001). The impact of gun laws on police deaths. Journal of Law and Economics 44(S2), pp. 635-657.

Odom Institute (2015). North carolina vital statistics dataverse.

Olson, D. E. and M. D. Maltz (2001). Righttocarry concealed weapon laws and homicide in large u.s. counties: The effect on weapon types, victim characteristics, and victimoffender relationships. Journal of Law and Economics 44(S2), pp. 747-770.

Ours, J. C. and B. Vollaard (2015). The engine immobiliser: A non-starter for car thieves. The Economic Journal.

Pew Research Center (2013, March). Why own a gun? protection is now top reason. http://www.people-press.org/2013/03/12/why-own-a-gun-protection-is-now-top-reason.

Philipson, T. J. and R. A. Posner (1996). The economic epidemiology of crime. Journal of Law and Economics, 405-433.

Plassmann, F. and T. N. Tideman (2001). Does the right to carry concealed handguns deter countable crimes? only a count analysis can say. Journal of Law and Economics 44 , $771-798$.

Pope, J. C. (2008). Fear of crime and housing prices: Household reactions to sex offender registries. Journal of Urban Economics 64(3), 601-614. 
Rubin, P. H. and H. Dezhbakhsh (2003). The effect of concealed handgun laws on crime: beyond the dummy variables. International Review of Law and Economics 23(2), 199-216.

Salm, M. and V. Vollaard (2016, January). How risk perceptions evolve after a change of environment. Working Paper.

Thompson, J. A. and R. Stidham (2010). Packing heat in the tar heel state: A county-level assessment of concealed carry permits. Criminal Justice Review 35(1), 52-66.

US Census Bureau (2012). Geographic Areas Reference Manual. General Books.

Vollaard, B. and J. C. Van Ours (2011). Does regulation of built-in security reduce crime? evidence from a natural experiment*. The Economic Journal 121(552), 485-504.

Wooldridge, J. M. (1997). Quasi-likelihood methods for count data. Handbook of applied econometrics 2, 352-406. 


\section{Figures and Tables}

Figure 1: Monthly Concealed-Carry Applications in North Carolina

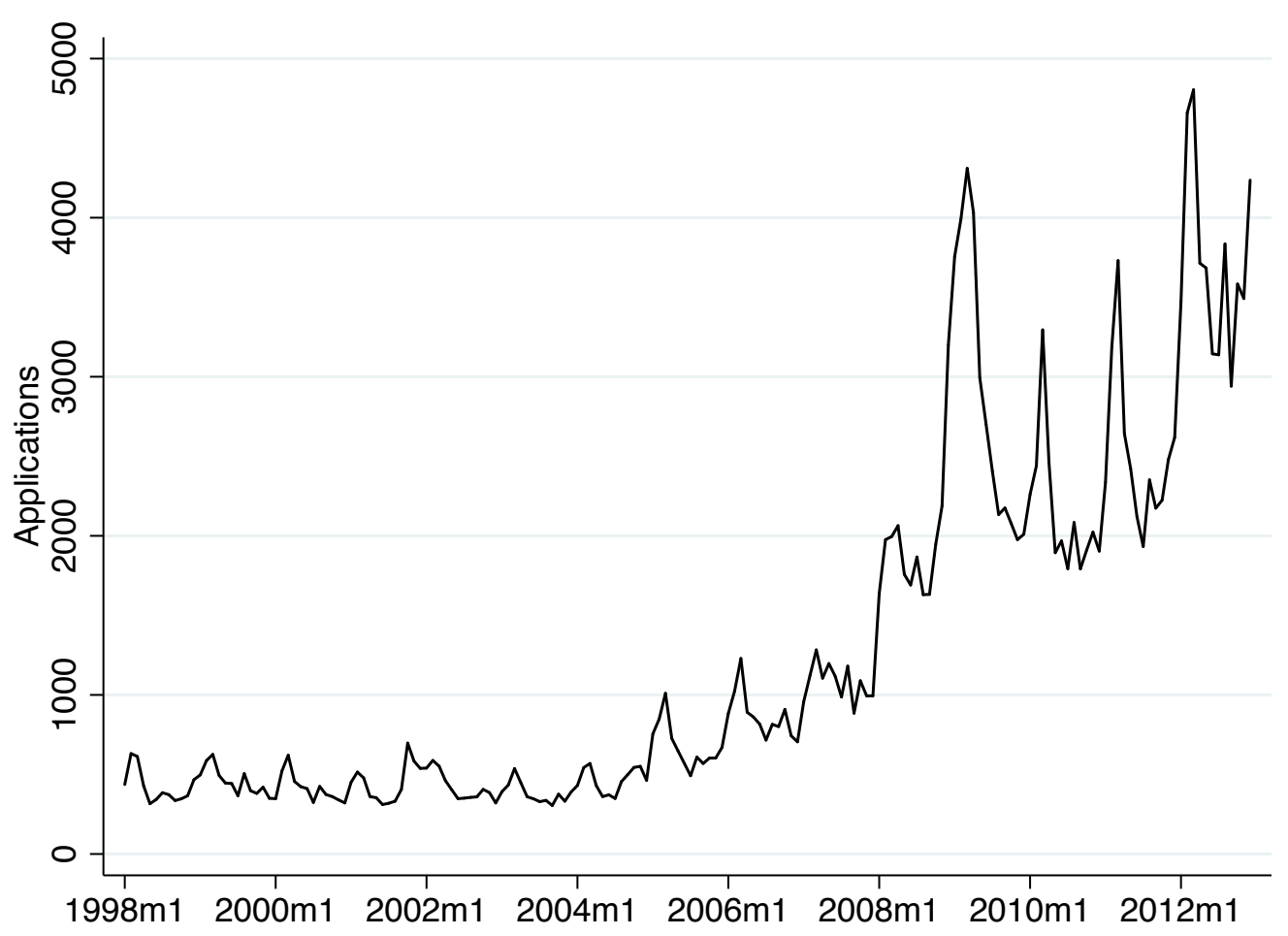


Figure 2: Estimated Effect of Homicides on Concealed Carry Applications by City Size

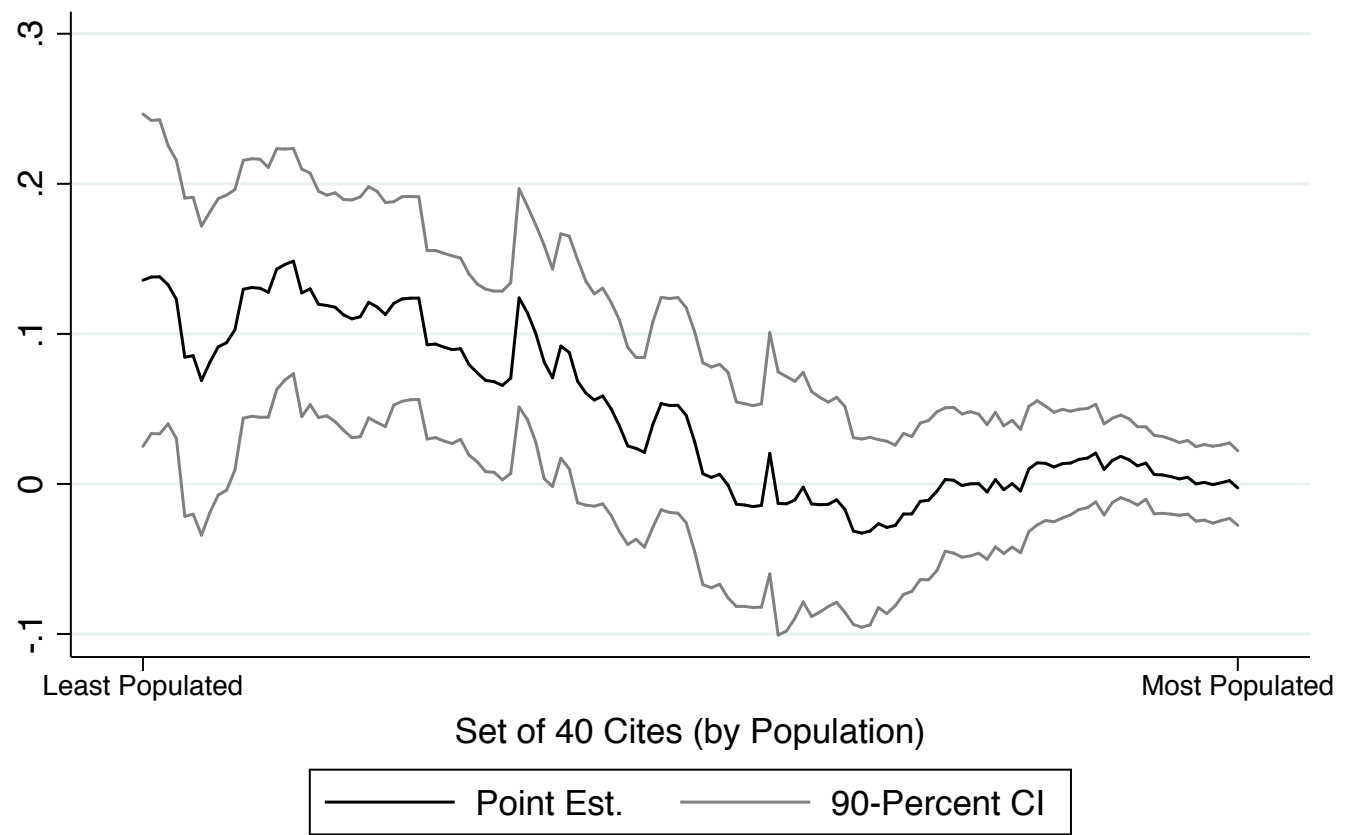

Estimates are obtained from using a moving sample size of 40 cities, starting with the 40 least populated cities in the data (far left) and incrementally moving to the 40 most populated cities in the data (far right). 
Table 1: Summary Statistics

\begin{tabular}{|c|c|c|c|}
\hline & $\begin{array}{c}(1) \\
\text { All Cities }\end{array}$ & $\begin{array}{c}(2) \\
\text { Below Median }\end{array}$ & $\begin{array}{c}(3) \\
\text { Above Median }\end{array}$ \\
\hline \multicolumn{4}{|c|}{ Panel A: Monthly Permit Applications } \\
\hline All & $\begin{array}{c}7.500 \\
(16.146)\end{array}$ & $\begin{array}{c}2.997 \\
(4.479)\end{array}$ & $\begin{array}{c}11.881 \\
(21.349)\end{array}$ \\
\hline Rate (per 10,000) & $\begin{array}{c}5.288 \\
(8.212)\end{array}$ & $\begin{array}{c}6.868 \\
(10.289)\end{array}$ & $\begin{array}{c}3.753 \\
(5.028)\end{array}$ \\
\hline Black & $\begin{array}{c}0.659 \\
(2.913)\end{array}$ & $\begin{array}{c}0.165 \\
(0.579)\end{array}$ & $\begin{array}{c}1.140 \\
(3.993)\end{array}$ \\
\hline White & $\begin{array}{c}6.684 \\
(13.427)\end{array}$ & $\begin{array}{c}2.762 \\
(4.205)\end{array}$ & $\begin{array}{c}10.499 \\
(17.576)\end{array}$ \\
\hline Male & $\begin{array}{c}5.911 \\
(12.445)\end{array}$ & $\begin{array}{c}2.337 \\
(3.420)\end{array}$ & $\begin{array}{c}9.387 \\
(16.420)\end{array}$ \\
\hline Female & $\begin{array}{c}1.589 \\
(4.017)\end{array}$ & $\begin{array}{c}0.660 \\
(1.358)\end{array}$ & $\begin{array}{c}2.493 \\
(5.327)\end{array}$ \\
\hline White-Male & $\begin{array}{c}5.254 \\
(10.362)\end{array}$ & $\begin{array}{c}2.145 \\
(3.187)\end{array}$ & $\begin{array}{c}8.277 \\
(13.542)\end{array}$ \\
\hline White-Female & $\begin{array}{c}1.431 \\
(3.371)\end{array}$ & $\begin{array}{c}0.616 \\
(1.304)\end{array}$ & $\begin{array}{l}2.222 \\
(4.414)\end{array}$ \\
\hline Black-Male & $\begin{array}{c}0.531 \\
(2.205)\end{array}$ & $\begin{array}{c}0.137 \\
(0.495)\end{array}$ & $\begin{array}{c}0.914 \\
(3.009)\end{array}$ \\
\hline Black-Female & $\begin{array}{c}0.128 \\
(0.830)\end{array}$ & $\begin{array}{c}0.028 \\
(0.186)\end{array}$ & $\begin{array}{c}0.225 \\
(1.143)\end{array}$ \\
\hline Ages 21-39 & $\begin{array}{l}2.776 \\
(7.054)\end{array}$ & $\begin{array}{l}1.019 \\
(1.983)\end{array}$ & $\begin{array}{l}4.484 \\
(9.402)\end{array}$ \\
\hline Ages $40-59$ & $\begin{array}{c}3.267 \\
(6.819)\end{array}$ & $\begin{array}{l}1.316 \\
(2.099)\end{array}$ & $\begin{array}{c}5.164 \\
(8.951)\end{array}$ \\
\hline Ages 60 plus & $\begin{array}{l}1.458 \\
(3.097)\end{array}$ & $\begin{array}{c}0.661 \\
(1.323)\end{array}$ & $\begin{array}{c}2.232 \\
(4.001)\end{array}$ \\
\hline Panel B: Monthly Homic & & & \\
\hline Homicide Indicator & $\begin{array}{c}0.110 \\
(0.313)\end{array}$ & $\begin{array}{c}0.029 \\
(0.169)\end{array}$ & $\begin{array}{c}0.188 \\
(0.391)\end{array}$ \\
\hline Homicides & $\begin{array}{c}0.181 \\
(0.698)\end{array}$ & $\begin{array}{c}0.030 \\
(0.177)\end{array}$ & $\begin{array}{c}0.327 \\
(0.941)\end{array}$ \\
\hline Homicides Normalized & $\begin{array}{l}-0.010 \\
(0.889)\end{array}$ & $\begin{array}{l}-0.026 \\
(0.714)\end{array}$ & $\begin{array}{c}0.005 \\
(1.032)\end{array}$ \\
\hline Homicide Rate (per 10,000) & $\begin{array}{c}0.066 \\
(0.329)\end{array}$ & $\begin{array}{c}0.069 \\
(0.426)\end{array}$ & $\begin{array}{c}0.063 \\
(0.192)\end{array}$ \\
\hline Gun Homicide & $\begin{array}{c}0.128 \\
(0.559)\end{array}$ & $\begin{array}{c}0.020 \\
(0.147)\end{array}$ & $\begin{array}{c}0.233 \\
(0.758)\end{array}$ \\
\hline Other Homicide & $\begin{array}{c}0.053 \\
(0.272)\end{array}$ & $\begin{array}{c}0.010 \\
(0.100)\end{array}$ & $\begin{array}{c}0.095 \\
(0.365)\end{array}$ \\
\hline Population & $\begin{array}{c}2.781 \\
(7.329)\end{array}$ & $\begin{array}{c}0.457 \\
(0.168)\end{array}$ & $\begin{array}{c}5.042 \\
(9.776)\end{array}$ \\
\hline
\end{tabular}

Standard deviations are displayed in parentheses. Summary statistics are calculated from city-by-month level data. There are 30,180 city-by-month observations. 14,880 are at or below the median population and 15,300 observations are above the median population. 
Table 2: Main Results: Estimated Effect of Homicides (Normalized) on Concealed Carry Applications

\section{$(1)$}

Panel A: All Cities $(n=170)$

Homicides (norm.) this month

Homicides (norm.) last month

Homicides (norm.) two months prior

Number of observations

Panel B: Below Median Pop. $(n=85)$

Homicides (norm.) this month

Homicides (norm.) last month

Homicides (norm.) two months prior

Number of observations

Panel C: Above Median Pop. $(n=85)$

Homicides (norm.) this month

Homicides (norm.) last month

Homicides (norm.) two months prior

Number of observations

City Fixed Effects

Year Fixed Effects

Month Fixed Effects

City by Year Fixed Effects

County Linear Time Trend

$\begin{array}{ccc}0.003 & 0.005 & 0.003 \\ (0.005) & (0.005) & (0.004) \\ 0.000 & 0.002 & 0.001 \\ (0.005) & (0.006) & (0.005) \\ -0.002 & -0.000 & -0.001 \\ (0.004) & (0.004) & (0.004) \\ 30,180 & 30,180 & 30,180\end{array}$

$\begin{array}{ccc}-0.003 & 0.003 & 0.001 \\ (0.011) & (0.011) & (0.011) \\ 0.021^{* * *} & 0.028^{* * *} & 0.025^{* * *} \\ (0.008) & (0.008) & (0.008) \\ 0.016 & 0.024^{* *} & 0.022^{* *} \\ (0.010) & (0.010) & (0.010) \\ 14,880 & 14,880 & 14,880\end{array}$

$\begin{array}{lll}0.002 & 0.004 & 0.003\end{array}$

$\begin{array}{lll}(0.006) & (0.005) \quad(0.005)\end{array}$

$\begin{array}{lll}-0.003 & -0.001 & -0.003\end{array}$

$\begin{array}{lll}(0.006) & (0.006) \quad(0.006)\end{array}$

$\begin{array}{lll}-0.004 & -0.003 & -0.004\end{array}$

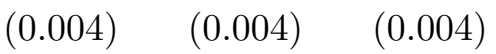

$15,300 \quad 15,300 \quad 15,300$

$\begin{array}{ccc}\text { Yes } & - & - \\ \text { Yes } & - & - \\ \text { Yes } & \text { Yes } & \text { Yes } \\ \text { No } & \text { Yes } & \text { Yes } \\ \text { No } & \text { No } & \text { Yes }\end{array}$

Notes: The dependent variable is a city's monthly number of new concealed-carry permit applications. Standard errors (in parentheses) are corrected for possible clustering at the city level.

$* 0.10, * * 0.05$ and ${ }^{* * *} 0.01$ denote significance levels. 
Table 3: Robustness Checks: Estimated Effect of Homicides on Concealed-Carry Applications

\begin{tabular}{lccc}
\hline \hline & $(1)$ & $(2)$ & $(3)$ \\
\hline Panel A: Normalized Homicides & & & \\
Homicides (norm.) this month & 0.001 & 0.001 & 0.001 \\
& $(0.011)$ & $(0.010)$ & $(0.011)$ \\
Homicides (norm.) last month & $0.025^{* * *}$ & $0.027^{* * *}$ & $0.025^{* * *}$ \\
& $(0.008)$ & $(0.007)$ & $(0.008)$ \\
Homicides (norm.) two months prior & $0.022^{* *}$ & $0.020^{* *}$ & $0.022^{* *}$ \\
& $(0.010)$ & $(0.009)$ & $(0.010)$ \\
& & & \\
Panel B: Homicide Dummy Variable & & & \\
Homicide this month & 0.037 & 0.049 & 0.039 \\
& $(0.046)$ & $(0.044)$ & $(0.046)$ \\
Homicide last month & $0.103^{* * *}$ & $0.105^{* * *}$ & $0.103^{* * *}$ \\
& $(0.037)$ & $(0.034)$ & $(0.038)$ \\
Homicide two months prior & $0.118^{* *}$ & $0.093^{* *}$ & $0.117^{* *}$ \\
& $(0.049)$ & $(0.042)$ & $(0.049)$ \\
Month Fixed Effects & Yes & - & Yes \\
City by Year Fixed Effects & Yes & Yes & Yes \\
County Linear Time Trend & Yes & No & - \\
Year by Month Fixed Effects & No & Yes & No \\
City Linear Time Trend & No & No & Yes \\
Number of observations & 14,880 & 14,880 & 14,880 \\
\hline \hline
\end{tabular}

Notes: The dependent variable is a city's monthly number of new concealed-carry permit applications. Standard errors (in parentheses) are corrected for possible clustering at the city level.

* $0.10, * * 0.05$ and ${ }^{* * *} 0.01$ denote significance levels. 
Table 4: Dynamic Effects of Homicides on Concealed-Carry Applications

\begin{tabular}{|c|c|c|c|c|c|c|c|}
\hline & $(1)$ & $(2)$ & $(3)$ & $(4)$ & $(5)$ & $(6)$ & $(7)$ \\
\hline \multicolumn{8}{|l|}{ Homicide Dummy Variable } \\
\hline Homicide five months after & & & & & & & $\begin{array}{c}-0.058 \\
(0.041)\end{array}$ \\
\hline Homicide four months after & & & & & & $\begin{array}{c}0.027 \\
(0.041)\end{array}$ & $\begin{array}{c}0.019 \\
(0.042)\end{array}$ \\
\hline Homicide three months after & & & & & $\begin{array}{c}-0.068^{*} \\
(0.040)\end{array}$ & $\begin{array}{l}-0.055 \\
(0.043)\end{array}$ & $\begin{array}{c}-0.063 \\
(0.042)\end{array}$ \\
\hline Homicide two months after & & & & $\begin{array}{c}-0.051 \\
(0.047)\end{array}$ & $\begin{array}{c}-0.058 \\
(0.049)\end{array}$ & $\begin{array}{l}-0.052 \\
(0.051)\end{array}$ & $\begin{array}{c}-0.062 \\
(0.052)\end{array}$ \\
\hline Homicide next month & & & $\begin{array}{c}0.068^{*} \\
(0.039)\end{array}$ & $\begin{array}{c}0.065 \\
(0.041)\end{array}$ & $\begin{array}{c}0.059 \\
(0.042)\end{array}$ & $\begin{array}{c}0.066 \\
(0.043)\end{array}$ & $\begin{array}{c}0.055 \\
(0.044)\end{array}$ \\
\hline Homicide this month & & $\begin{array}{c}0.040 \\
(0.047)\end{array}$ & $\begin{array}{c}0.047 \\
(0.047)\end{array}$ & $\begin{array}{c}0.045 \\
(0.049)\end{array}$ & $\begin{array}{c}0.039 \\
(0.050)\end{array}$ & $\begin{array}{c}0.044 \\
(0.052)\end{array}$ & $\begin{array}{c}0.033 \\
(0.055)\end{array}$ \\
\hline Homicide last month & $\begin{array}{c}0.101^{* * *} \\
(0.037)\end{array}$ & $\begin{array}{c}0.106^{* * *} \\
(0.038)\end{array}$ & $\begin{array}{c}0.109 * * * \\
(0.039)\end{array}$ & $\begin{array}{c}0.102^{* *} \\
(0.041)\end{array}$ & $\begin{array}{c}0.096^{* *} \\
(0.041)\end{array}$ & $\begin{array}{c}0.106^{* *} \\
(0.047)\end{array}$ & $\begin{array}{c}0.108^{* *} \\
(0.048)\end{array}$ \\
\hline Homicide two months prior & $\begin{array}{c}0.119^{* *} \\
(0.049)\end{array}$ & $\begin{array}{c}0.122^{* *} \\
(0.050)\end{array}$ & $\begin{array}{c}0.132^{* *} \\
(0.052)\end{array}$ & $\begin{array}{c}0.126^{* *} \\
(0.052)\end{array}$ & $\begin{array}{c}0.117^{* *} \\
(0.055)\end{array}$ & $\begin{array}{c}0.123^{* *} \\
(0.057)\end{array}$ & $\begin{array}{c}0.127^{* *} \\
(0.059)\end{array}$ \\
\hline Homicide three months prior & $\begin{array}{c}0.029 \\
(0.042)\end{array}$ & $\begin{array}{c}0.032 \\
(0.042)\end{array}$ & $\begin{array}{c}0.042 \\
(0.044)\end{array}$ & $\begin{array}{c}0.027 \\
(0.048)\end{array}$ & $\begin{array}{c}0.018 \\
(0.048)\end{array}$ & $\begin{array}{c}0.029 \\
(0.048)\end{array}$ & $\begin{array}{c}0.028 \\
(0.049)\end{array}$ \\
\hline Month Fixed Effects & Yes & Yes & Yes & Yes & Yes & Yes & Yes \\
\hline City by Year Fixed Effects & Yes & Yes & Yes & Yes & Yes & Yes & Yes \\
\hline County Linear Time Trend & Yes & Yes & Yes & Yes & Yes & Yes & Yes \\
\hline Number of observations & 14,880 & 14,880 & 14,797 & 14,714 & 14,631 & 14,548 & 14,465 \\
\hline
\end{tabular}

Notes: The dependent variable is a city's monthly number of new concealed-carry permit applications. Standard errors (in parentheses) are corrected for possible clustering at the city level.

$* 0.10, * * 0.05$ and $* * * 0.01$ denote significance levels. 
Table 5: Estimated Effects by Homicide Type and Other External Causes of Death

\begin{tabular}{lcccccc}
\hline \hline & $(1)$ & $(2)$ & $(3)$ & $(4)$ & $(5)$ & $(6)$ \\
& Any & Gun & Other & Motor & & $\begin{array}{c}\text { Drug } \\
\text { Overdose }\end{array}$ \\
\hline \multirow{3}{*}{ Homicide } & Homicide & Homicide & Vehicle & Suicide & Overde previous two months \\
& $0.115^{* * *}$ & $0.149^{* * *}$ & 0.012 & -0.033 & -0.023 & 0.018 \\
Month FE & $(0.037)$ & $(0.044)$ & $(0.053)$ & $(0.021)$ & $(0.023)$ & $(0.022)$ \\
City by Year FE & Yes & Yes & Yes & Yes & Yes & Yes \\
County Trend & Yes & Yes & Yes & Yes & Yes & Yes \\
Number of observations & Yes & Yes & Yes & Yes & Yes & Yes \\
Mean mortality & 14,880 & 14,880 & 14,880 & 14,880 & 14,880 & 14,880 \\
\hline \hline
\end{tabular}

Notes: The dependent variable is a city's monthly number of new concealed-carry permit applications. Standard errors (in parentheses) are corrected for possible clustering at the city level.

$* 0.10, * * 0.05$ and $* * * 0.01$ denote significance levels. 
Table 6: Estimated Effects by Applicant Characteristics

\begin{tabular}{lcccccccc}
\hline \hline & $(1)$ & $(2)$ & $(3)$ & $(4)$ & $(5)$ & $(6)$ & $(7)$ & $(8)$ \\
& All & Black & White & Male & Female & Ages 21-39 & Ages 40-59 & Ages 60+ \\
\hline & & & & & & & & \\
Homicide previous two months & $0.115^{* * *}$ & 0.005 & $0.135^{* * *}$ & $0.127^{* * *}$ & 0.073 & $0.100^{*}$ & $0.140^{* * *}$ & 0.091 \\
& $(0.037)$ & $(0.095)$ & $(0.038)$ & $(0.032)$ & $(0.075)$ & $(0.060)$ & $(0.042)$ & $(0.058)$ \\
Month FE & Yes & Yes & Yes & Yes & Yes & Yes & Yes & Yes \\
City by Year FE & Yes & Yes & Yes & Yes & Yes & Yes & Yes & Yes \\
County Trend & Yes & Yes & Yes & Yes & Yes & Yes & Yes & Yes \\
Number of observations & 14,880 & 8,280 & 14,736 & 14,844 & 12,732 & 13,776 & 14,472 & 13,032 \\
\hline \hline
\end{tabular}

Notes: The dependent variable is a city's monthly number of new concealed-carry permit applications. Standard errors (in parentheses) are corrected for possible clustering at the city level.

$* 0.10, * * 0.05$ and ${ }^{* * *} 0.01$ denote significance levels. 
Table 7: Estimated Effects by Victim Salience

\begin{tabular}{|c|c|c|c|c|c|c|c|c|}
\hline & $\begin{array}{c}(1) \\
\text { Black }\end{array}$ & $\begin{array}{c}(2) \\
\text { White }\end{array}$ & $\begin{array}{c}(3) \\
\text { Male }\end{array}$ & $\begin{array}{c}(4) \\
\text { Female }\end{array}$ & $\begin{array}{c}(5) \\
\text { Black-Male }\end{array}$ & $\begin{array}{c}(6) \\
\text { White-Male }\end{array}$ & $\begin{array}{c}(7) \\
\text { Black-Female } \\
\end{array}$ & $\begin{array}{c}(8) \\
\text { White-Female }\end{array}$ \\
\hline Other Victim & $\begin{array}{c}0.005 \\
(0.153)\end{array}$ & $\begin{array}{c}0.182^{* * *} \\
(0.051)\end{array}$ & $\begin{array}{c}0.097^{* *} \\
(0.046)\end{array}$ & $\begin{array}{c}0.031 \\
(0.081)\end{array}$ & $\begin{array}{l}-0.161 \\
(0.145)\end{array}$ & $\begin{array}{c}0.166^{* * *} \\
(0.041)\end{array}$ & $\begin{array}{l}-0.022 \\
(0.249)\end{array}$ & $\begin{array}{c}0.070 \\
(0.087)\end{array}$ \\
\hline Black Victim & $\begin{array}{l}0.005 \\
(0.115)\end{array}$ & & & & & & & \\
\hline White Victim & & $\begin{array}{l}0.081^{*} \\
(0.045)\end{array}$ & & & & & & \\
\hline Male Victim & & & $\begin{array}{c}0.133^{* * * *} \\
(0.036)\end{array}$ & & & & & \\
\hline Female Victim & & & & $\begin{array}{c}0.258^{* *} \\
(0.115)\end{array}$ & & & & \\
\hline Black-Male Victim & & & & & $\begin{array}{c}0.062 \\
(0.117)\end{array}$ & & & \\
\hline White-Male Victim & & & & & & $\begin{array}{c}0.123^{* *} \\
(0.051)\end{array}$ & & \\
\hline Black-Female Victim & & & & & & & $\begin{array}{l}0.938^{*} \\
(0.511)\end{array}$ & \\
\hline White-Female Victim & & & & & & & & $\begin{array}{c}0.180 \\
(0.146)\end{array}$ \\
\hline Month FE & Yes & Yes & Yes & Yes & Yes & Yes & Yes & Yes \\
\hline City by Year FE & Yes & Yes & Yes & Yes & Yes & Yes & Yes & Yes \\
\hline County Trend & Yes & Yes & Yes & Yes & Yes & Yes & Yes & Yes \\
\hline Number of observations & 8,280 & 14,736 & 14,844 & 12,732 & 7,812 & 14,676 & 2,916 & 12,240 \\
\hline
\end{tabular}

Notes: The dependent variable is a city's monthly number of new concealed-carry permit applications. Standard errors (in parentheses) are corrected for possible clustering at the city level.

$* 0.10, * * 0.05$ and ${ }^{* * *} 0.01$ denote significance levels. 


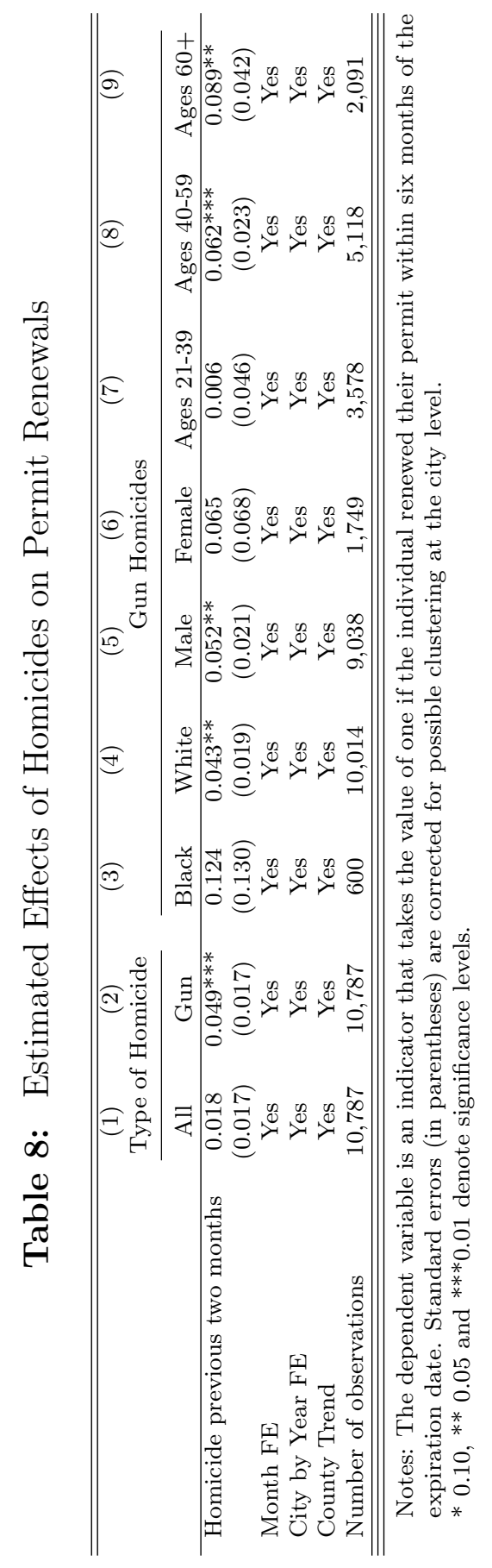


Table 9: Estimated Effects of Homicides Using UCR Data

\begin{tabular}{lccc}
\hline \hline & $(1)$ & $(2)$ & $(3)$ \\
& All Cities & Below Median & Above Median \\
\hline Panel A: Homicide Dummy & & & \\
Homicide this month & 0.019 & $0.200^{* * *}$ & 0.008 \\
& $(0.015)$ & $(0.042)$ & $(0.015)$ \\
Homicide two months prior & 0.016 & $0.122^{* *}$ & 0.010 \\
& $(0.017)$ & $(0.056)$ & $(0.018)$ \\
Number of observations & 22,414 & 11,467 & 10,947 \\
& & & \\
Panel B: Normalized Homicides & & & \\
Homicides (norm.) last month & $0.013^{* *}$ & $0.031^{* * *}$ & 0.008 \\
& $(0.006)$ & $(0.008)$ & $(0.008)$ \\
Homicides (norm.) two months prior & 0.003 & $0.022^{* *}$ & -0.001 \\
& $(0.006)$ & $(0.010)$ & $(0.008)$ \\
Month FE & Yes & Yes & Yes \\
City by Year FE & Yes & Yes & Yes \\
County Trend & Yes & Yes & Yes \\
Number of observations & 22,414 & 11,467 & 10,947 \\
\hline \hline
\end{tabular}

Notes: The dependent variable is a city's monthly number of new concealed-carry permit applications.

Standard errors (in parentheses) are corrected for possible clustering at the city level.

$* 0.10, * * 0.05$ and $* * * 0.01$ denote significance levels. 


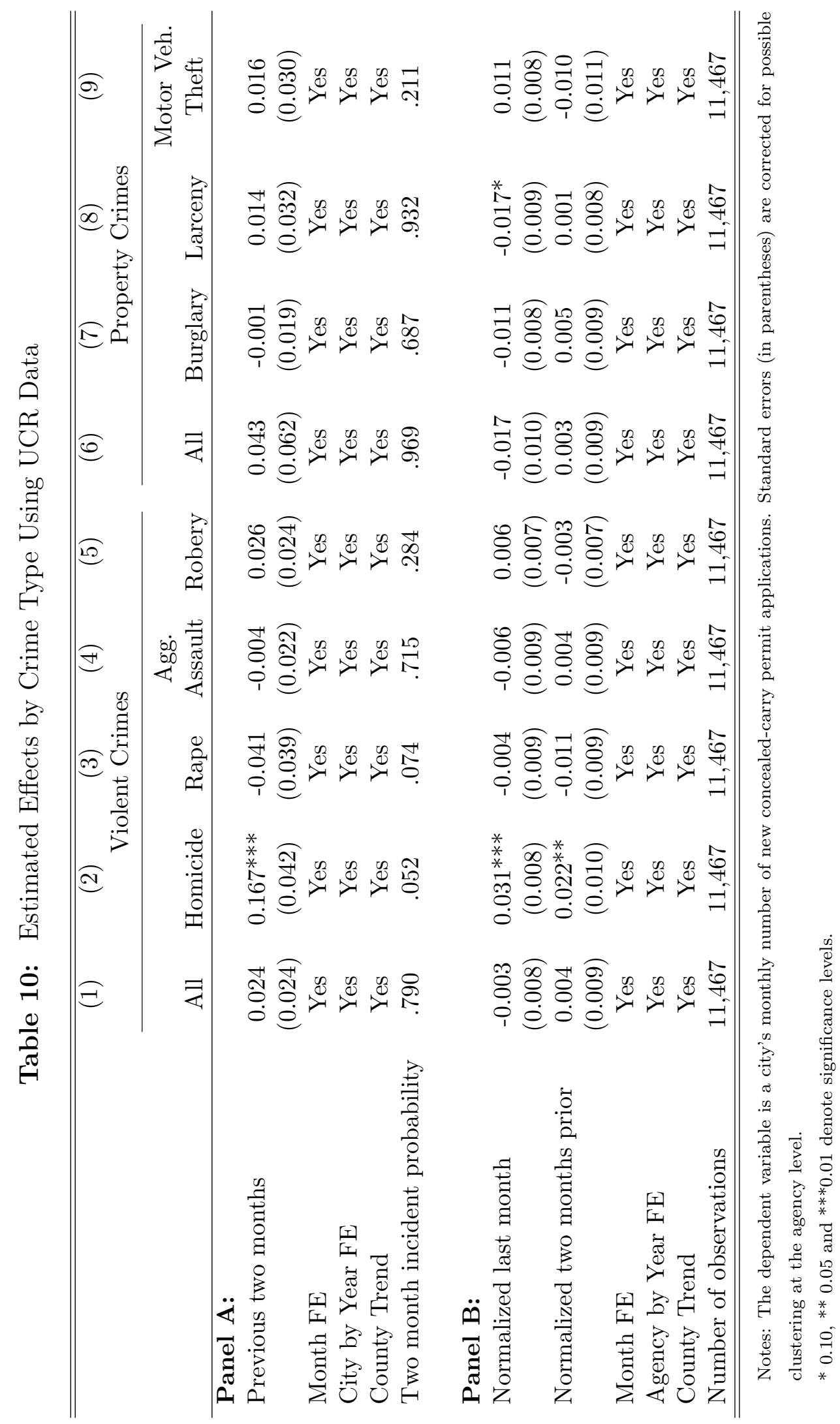


Table 11: Estimated Effects of Homicidse Using Disaggregated Data

\begin{tabular}{lccc}
\hline \hline & $(1)$ & $(2)$ & $(3)$ \\
& Census Tracts & Block Groups & Blocks \\
\hline Previous two months & -0.034 & -0.021 & $0.268^{* *}$ \\
& $(0.047)$ & $(0.069)$ & $(0.131)$ \\
Month FE & Yes & Yes & Yes \\
Geo. Measure by Year FE & Yes & Yes & Yes \\
City Trend & Yes & Yes & Yes \\
Number of observations & 6,034 & 12,275 & 46,112 \\
\hline \hline
\end{tabular}

Notes: The dependent variable is the monthly number of new concealed-carry permit applications within the geographic measure. Standard errors (in parentheses) are corrected for possible clustering at the level of the geographic aggregation.

$* 0.10, * * 0.05$ and ${ }^{* * *} 0.01$ denote significance levels. 
Table 12: Estimated Effects by Type of Crime

\begin{tabular}{lcccccc}
\hline \hline & $(1)$ & $(2)$ & $(3)$ & $(4)$ & $(5)$ & $(6)$ \\
& Any & & & & & \\
& Homicide & Assault & Burglary & Robbery & Theft & Vandalism \\
\hline Previous two months & $0.268^{* *}$ & $0.066^{*}$ & 0.012 & -0.020 & -0.029 & 0.072 \\
& $(0.131)$ & $(0.039)$ & $(0.041)$ & $(0.077)$ & $(0.038)$ & $(0.056)$ \\
Month FE & Yes & Yes & Yes & Yes & Yes & Yes \\
Block by Year FE & Yes & Yes & Yes & Yes & Yes & Yes \\
City Trend & Yes & Yes & Yes & Yes & Yes & Yes \\
Number of observations & 46,112 & 46,112 & 46,112 & 46,112 & 46,112 & 46,112 \\
Mean & 0.004 & 0.233 & 0.185 & 0.033 & 0.278 & 0.089 \\
\hline \hline
\end{tabular}

Notes: The dependent variable is a census block's monthly number of new concealed-carry permit applications.

Standard errors (in parentheses) are corrected for possible clustering at the block level.

$* 0.10, * * 0.05$ and $* * * 0.01$ denote significance levels. 


\section{A Appendix: Tables}

Figure 1: Estimated effect of normalized homicide on concealed-carry applications by city size

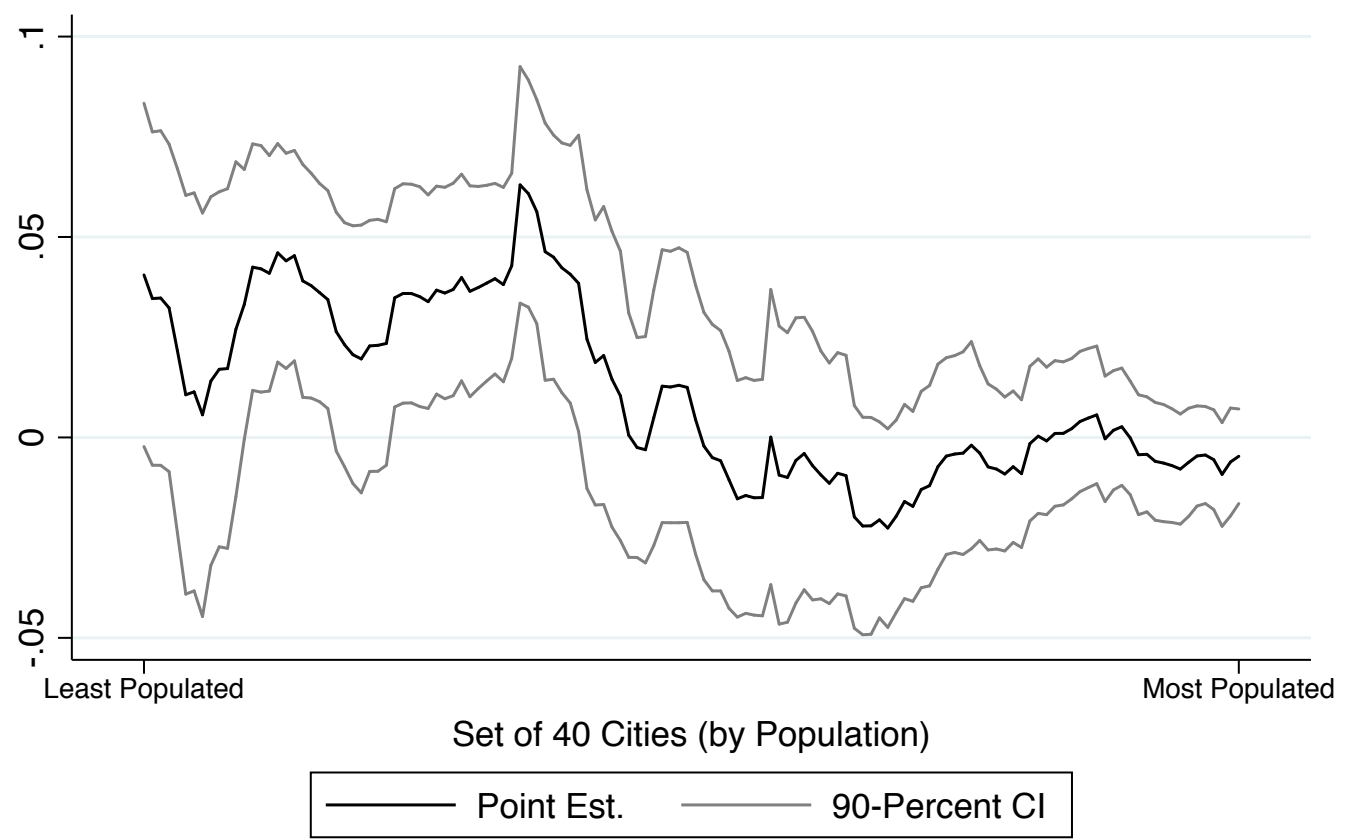

Estimates are obtained from using a moving sample size of 40 cities, starting with the 40 least populated cities in the data (far left) and incrementally moving to the 40 most populated cities in the data (far right). 
Table A1: Main Results: Estimated Effect of Homicide (Dummy Variable) on Concealed Carry Applications

(1)

Panel A: All Cities $(n=170)$

Homicide this month

Homicide last month

Homicide two months prior

Number of observations

Panel B: Below Median Pop. $(n=85)$

Homicide this month

Homicide last month

Homicide two months prior

Number of observations

Panel C: Above Median Pop. $(\mathrm{n}=85)$

Homicide this month

Homicide last month

Homicide two months prior

Number of observations

City Fixed Effects

Year Fixed Effects

Month Fixed Effects

City by Year Fixed Effects

County Linear Time Trend

$\begin{array}{ccc}0.007 & 0.007 & 0.003 \\ (0.014) & (0.016) & (0.016) \\ -0.010 & -0.012 & -0.016 \\ (0.013) & (0.016) & (0.015) \\ 0.012 & 0.010 & 0.008 \\ (0.011) & (0.011) & (0.011) \\ 30,180 & 30,180 & 30,180\end{array}$

$\begin{array}{ccc}0.020 & 0.041 & 0.037 \\ (0.044) & (0.047) & (0.046) \\ 0.086^{* *} & 0.111^{* * *} & 0.103^{* * *} \\ (0.034) & (0.037) & (0.037) \\ 0.099^{* *} & 0.128^{* * *} & 0.118^{* *} \\ (0.049) & (0.049) & (0.049) \\ 14,880 & 14,880 & 14,880\end{array}$

$\begin{array}{lll}0.005 & 0.003 & -0.000\end{array}$

$\begin{array}{lll}(0.015) & (0.017) \quad(0.017)\end{array}$

$\begin{array}{lll}-0.016 & -0.020 & -0.023\end{array}$

$\begin{array}{lll}(0.014) \quad(0.016) \quad(0.016) & 0.03)\end{array}$

$\begin{array}{lll}0.008 & 0.003 & 0.003\end{array}$

$(0.011) \quad(0.011) \quad(0.011)$
$15,300)$

$15,300 \quad 15,300 \quad 15,300$

Notes: The dependent variable is a city's monthly number of new concealed-carry permit applications. Standard errors (in parentheses) are corrected for possible clustering at the city level.

$* 0.10, * * 0.05$ and $* * * 0.01$ denote significance levels. 
Table A2: Robustness Checks: Estimated Effect of Homicide (Rates and Levels) on Concealed-Carry Applications

\section{(1)}

Panel A: Homicides Rates

Homicide rate this month

Homicide rate last month

Homicide rate two months prior

Month Fixed Effects

City by Year Fixed Effects

County Linear Time Trend

Month by Year Fixed Effects

City Linear Time Trend

Number of observations

Panel B: Homicide Levels

Number of homicides

Number of homicides last month

Number of homicides two months prior

Month Fixed Effects

City by Year Fixed Effects

County Linear Time Trend

Month by Year Fixed Effects

City Linear Time Trend

Number of observations

$(2)$

$\begin{array}{ccc}0.013 & 0.019 & 0.013 \\ (0.018) & (0.018) & (0.018) \\ 0.038^{* *} & 0.038^{* *} & 0.037^{* *} \\ (0.016) & (0.016) & (0.016) \\ 0.047^{* * *} & 0.037^{* *} & 0.046^{* * *} \\ (0.017) & (0.016) & (0.017) \\ \text { Yes } & - & \text { Yes } \\ \text { Yes } & \text { Yes } & \text { Yes } \\ \text { Yes } & \text { No } & - \\ \text { No } & \text { Yes } & \text { No } \\ \text { No } & \text { No } & \text { Yes } \\ 14,880 & 14,880 & 14,880\end{array}$

\begin{tabular}{ccc}
0.027 & 0.040 & 0.029 \\
$(0.042)$ & $(0.042)$ & $(0.043)$ \\
$0.105^{* * *}$ & $0.106^{* * *}$ & $0.104^{* * *}$ \\
$(0.036)$ & $(0.034)$ & $(0.036)$ \\
$0.109^{* *}$ & $0.089^{* *}$ & $0.107^{* *}$ \\
$(0.044)$ & $(0.039)$ & $(0.044)$ \\
Yes & - & Yes \\
Yes & Yes & Yes \\
Yes & No & - \\
No & Yes & No \\
No & No & Yes \\
14,880 & 14,880 & 14,880 \\
\hline
\end{tabular}

Notes: The dependent variable is a city's monthly number of new concealed-carry permit applications. Standard errors (in parentheses) are corrected for possible clustering at the city level.

* $0.10, * * 0.05$ and ${ }^{* * *} 0.01$ denote significance levels. 
Table A3: Dynamic Effects of Homicide (Normalized) on Concealed Carry Applications

\begin{tabular}{|c|c|c|c|c|c|c|c|}
\hline & $(1)$ & $(2)$ & $(3)$ & $(4)$ & $(5)$ & $(6)$ & $(7)$ \\
\hline \multicolumn{8}{|l|}{ Normalized Homicides } \\
\hline Homicide five months after & & & & & & & $\begin{array}{c}-0.015^{*} \\
(0.008)\end{array}$ \\
\hline Homicide four months after & & & & & & $\begin{array}{l}-0.001 \\
(0.009)\end{array}$ & $\begin{array}{l}-0.003 \\
(0.010)\end{array}$ \\
\hline Homicide three months after & & & & & $\begin{array}{l}-0.008 \\
(0.009)\end{array}$ & $\begin{array}{l}-0.005 \\
(0.009)\end{array}$ & $\begin{array}{l}-0.008 \\
(0.008)\end{array}$ \\
\hline Homicide two months after & & & & $\begin{array}{l}-0.015 \\
(0.010)\end{array}$ & $\begin{array}{l}-0.015 \\
(0.011)\end{array}$ & $\begin{array}{l}-0.015 \\
(0.011)\end{array}$ & $\begin{array}{c}-0.017 \\
(0.011)\end{array}$ \\
\hline Homicide next month & & & $\begin{array}{c}0.004 \\
(0.009)\end{array}$ & $\begin{array}{c}0.004 \\
(0.009)\end{array}$ & $\begin{array}{c}0.004 \\
(0.009)\end{array}$ & $\begin{array}{c}0.004 \\
(0.009)\end{array}$ & $\begin{array}{c}0.002 \\
(0.009)\end{array}$ \\
\hline Homicide this month & & $\begin{array}{c}0.002 \\
(0.011)\end{array}$ & $\begin{array}{c}0.002 \\
(0.012)\end{array}$ & $\begin{array}{c}0.000 \\
(0.012)\end{array}$ & $\begin{array}{c}0.000 \\
(0.012)\end{array}$ & $\begin{array}{c}0.000 \\
(0.012)\end{array}$ & $\begin{array}{l}-0.000 \\
(0.013)\end{array}$ \\
\hline Homicide last month & $\begin{array}{c}0.027^{* * *} \\
(0.008)\end{array}$ & $\begin{array}{c}0.027^{* * *} \\
(0.008)\end{array}$ & $\begin{array}{c}0.028^{* * *} \\
(0.008)\end{array}$ & $\begin{array}{c}0.027^{* * *} \\
(0.008)\end{array}$ & $\begin{array}{c}0.027^{* * *} \\
(0.008)\end{array}$ & $\begin{array}{c}0.030^{* * *} \\
(0.009)\end{array}$ & $\begin{array}{c}0.031^{* * *} \\
(0.010)\end{array}$ \\
\hline Homicide two months prior & $\begin{array}{c}0.024^{* *} \\
(0.010)\end{array}$ & $\begin{array}{c}0.024^{* *} \\
(0.010)\end{array}$ & $\begin{array}{c}0.026^{* *} \\
(0.010)\end{array}$ & $\begin{array}{c}0.024^{* *} \\
(0.011)\end{array}$ & $\begin{array}{c}0.024^{* *} \\
(0.011)\end{array}$ & $\begin{array}{c}0.025^{* *} \\
(0.011)\end{array}$ & $\begin{array}{c}0.026^{* *} \\
(0.012)\end{array}$ \\
\hline Homicide three months prior & $\begin{array}{l}0.015^{*} \\
(0.009)\end{array}$ & $\begin{array}{l}0.015^{*} \\
(0.009)\end{array}$ & $\begin{array}{c}0.017^{*} \\
(0.010)\end{array}$ & $\begin{array}{c}0.015 \\
(0.010)\end{array}$ & $\begin{array}{c}0.014 \\
(0.010)\end{array}$ & $\begin{array}{c}0.015 \\
(0.010)\end{array}$ & $\begin{array}{c}0.015 \\
(0.011)\end{array}$ \\
\hline Month Fixed Effects & Yes & Yes & Yes & Yes & Yes & Yes & Yes \\
\hline City by Year Fixed Effects & Yes & Yes & Yes & Yes & Yes & Yes & Yes \\
\hline County Linear Time Trend & Yes & Yes & Yes & Yes & Yes & Yes & Yes \\
\hline Number of observations & 14,880 & 14,880 & 14,797 & 14,714 & 14,631 & 14,548 & 14,465 \\
\hline
\end{tabular}

Notes: The dependent variable is a city's monthly number of new concealed-carry permit applications. Standard errors (in parentheses) are corrected for possible clustering at the city level.

$* 0.10, * * 0.05$ and $* * * 0.01$ denote significance levels. 
Table A4: Estimated Effects Comparing NCSCHS and UCR Data

\begin{tabular}{lccc}
\hline \hline & $(1)$ & $(2)$ & $(3)$ \\
& NCSCHS & NCSCHS (rest.) & UCR \\
\hline Panel A: Normalized Homicides & & & \\
Homicides (norm.) this month & 0.002 & 0.001 & $0.013^{*}$ \\
& $(0.012)$ & $(0.013)$ & $(0.008)$ \\
& $0.025^{* * *}$ & $0.028^{* * *}$ & $0.033^{* * *}$ \\
Homicides (norm.) last month & $(0.009)$ & $(0.008)$ & $(0.008)$ \\
& $0.018^{*}$ & 0.018 & $0.023^{* *}$ \\
Homicides (norm.) two months prior & $(0.011)$ & $(0.011)$ & $(0.011)$ \\
& 12,192 & 11,467 & 11,467 \\
Number of observations & & & \\
& & & \\
Panel B: Homicide Dummy & 0.046 & 0.048 & $0.103^{* *}$ \\
Homicide this month & $(0.051)$ & $(0.053)$ & $(0.040)$ \\
& $0.107^{* * *}$ & $0.132^{* * *}$ & $0.207^{* * *}$ \\
Homicide this month & $(0.039)$ & $(0.037)$ & $(0.040)$ \\
& $0.109^{* *}$ & $0.116^{* *}$ & $0.133^{* *}$ \\
Homicide this month & $(0.055)$ & $(0.056)$ & $(0.056)$ \\
& Yes & Yes & Yes \\
Month FE & Yes & Yes & Yes \\
City by Year FE & Yes & Yes & Yes \\
County Trend & 12,192 & 11,467 & 11,467 \\
Number of observations & \multicolumn{2}{c}{. }
\end{tabular}

Notes: The dependent variable is a city's monthly number of new concealed-carry permit applications. Standard errors (in parentheses) are corrected for possible clustering at the city level.

$* 0.10, * * 0.05$ and ${ }^{* * *} 0.01$ denote significance levels. 
Table A5: Dynamic Effects of Homicides on Applications (UCR Data)

\begin{tabular}{|c|c|c|c|c|c|c|c|}
\hline & $(1)$ & $(2)$ & $(3)$ & $(4)$ & $(5)$ & $(6)$ & $(7)$ \\
\hline \multicolumn{8}{|l|}{ Homicide Dummy Variable } \\
\hline Homicide five months after & & & & & & & $\begin{array}{c}0.002 \\
(0.060)\end{array}$ \\
\hline Homicide four months after & & & & & & $\begin{array}{l}-0.018 \\
(0.063)\end{array}$ & $\begin{array}{l}-0.016 \\
(0.063)\end{array}$ \\
\hline Homicide three months after & & & & & $\begin{array}{l}-0.019 \\
(0.048)\end{array}$ & $\begin{array}{l}-0.018 \\
(0.048)\end{array}$ & $\begin{array}{l}-0.011 \\
(0.049)\end{array}$ \\
\hline Homicide two months after & & & & $\begin{array}{c}0.077 \\
(0.064)\end{array}$ & $\begin{array}{c}0.081 \\
(0.066)\end{array}$ & $\begin{array}{c}0.073 \\
(0.065)\end{array}$ & $\begin{array}{c}0.070 \\
(0.066)\end{array}$ \\
\hline Homicide next month & & & $\begin{array}{c}0.024 \\
(0.040)\end{array}$ & $\begin{array}{c}0.030 \\
(0.042)\end{array}$ & $\begin{array}{c}0.023 \\
(0.044)\end{array}$ & $\begin{array}{c}0.029 \\
(0.047)\end{array}$ & $\begin{array}{c}0.027 \\
(0.048)\end{array}$ \\
\hline Homicide this month & & $\begin{array}{c}0.102^{* *} \\
(0.040)\end{array}$ & $\begin{array}{c}0.095^{* *} \\
(0.042)\end{array}$ & $\begin{array}{c}0.095^{* *} \\
(0.045)\end{array}$ & $\begin{array}{c}0.092^{* *} \\
(0.046)\end{array}$ & $\begin{array}{c}0.101^{* *} \\
(0.047)\end{array}$ & $\begin{array}{c}0.099 * * \\
(0.048)\end{array}$ \\
\hline Homicide last month & $\begin{array}{c}0.202^{* * *} * \\
(0.042)\end{array}$ & $\begin{array}{c}0.210^{* * *} \\
(0.039)\end{array}$ & $\begin{array}{c}0.227^{* * *} \\
(0.038)\end{array}$ & $\begin{array}{c}0.235^{* * *} \\
(0.040)\end{array}$ & $\begin{array}{c}0.233^{* * *} \\
(0.042)\end{array}$ & $\begin{array}{c}0.231^{* * *} \\
(0.041)\end{array}$ & $\begin{array}{c}0.231^{* * * *} \\
(0.041)\end{array}$ \\
\hline Homicide two months prior & $\begin{array}{c}0.123^{* *} \\
(0.055)\end{array}$ & $\begin{array}{c}0.134^{* *} \\
(0.055)\end{array}$ & $\begin{array}{c}0.137^{* *} \\
(0.058)\end{array}$ & $\begin{array}{c}0.146^{* *} \\
(0.058)\end{array}$ & $\begin{array}{c}0.146^{* *} \\
(0.060)\end{array}$ & $\begin{array}{c}0.152^{* *} \\
(0.060)\end{array}$ & $\begin{array}{c}0.155^{* *} \\
(0.062)\end{array}$ \\
\hline Homicide three months prior & $\begin{array}{c}0.002 \\
(0.052)\end{array}$ & $\begin{array}{c}0.011 \\
(0.053)\end{array}$ & $\begin{array}{c}0.014 \\
(0.053)\end{array}$ & $\begin{array}{c}0.017 \\
(0.053)\end{array}$ & $\begin{array}{c}0.010 \\
(0.054)\end{array}$ & $\begin{array}{c}0.017 \\
(0.056)\end{array}$ & $\begin{array}{c}0.019 \\
(0.055)\end{array}$ \\
\hline Month Fixed Effects & Yes & Yes & Yes & Yes & Yes & Yes & Yes \\
\hline City by Year Fixed Effects & Yes & Yes & Yes & Yes & Yes & Yes & Yes \\
\hline County Linear Time Trend & Yes & Yes & Yes & Yes & Yes & Yes & Yes \\
\hline Number of observations & 11,392 & 11,392 & 11,325 & 11,257 & 11,189 & 11,121 & 11,053 \\
\hline
\end{tabular}

Notes: The dependent variable is a agency's monthly number of new concealed-carry permit applications. Standard errors (in parentheses) are corrected for possible clustering at the city level.

$* 0.10, * * 0.05$ and ${ }^{* * *} 0.01$ denote significance levels. 
Table A6: Summary Statistics: Charlotee, Raleigh, and Winstom-Salem

\begin{tabular}{|c|c|c|c|}
\hline & $\begin{array}{c}\text { (1) } \\
\text { Census Tracts }\end{array}$ & $\begin{array}{c}(2) \\
\text { Block Groups }\end{array}$ & $\begin{array}{c}(3) \\
\text { Blocks }\end{array}$ \\
\hline Applications & $\begin{array}{c}1.378 \\
(2.000)\end{array}$ & $\begin{array}{c}0.678 \\
(1.187)\end{array}$ & $\begin{array}{c}0.180 \\
(0.468)\end{array}$ \\
\hline Population & $\begin{array}{c}1,556.804 \\
(1,529.464)\end{array}$ & $\begin{array}{c}765.275 \\
(893.876)\end{array}$ & $\begin{array}{c}203.716 \\
(280.608)\end{array}$ \\
\hline Homicides & $\begin{array}{c}0.017 \\
(0.155)\end{array}$ & $\begin{array}{c}0.008 \\
(0.106)\end{array}$ & $\begin{array}{c}0.002 \\
(0.051)\end{array}$ \\
\hline Assaults & $\begin{array}{c}2.073 \\
(3.166)\end{array}$ & $\begin{array}{c}1.019 \\
(1.868)\end{array}$ & $\begin{array}{c}0.271 \\
(0.839)\end{array}$ \\
\hline Burglary & $\begin{array}{c}1.329 \\
(2.403)\end{array}$ & $\begin{array}{c}0.653 \\
(1.399)\end{array}$ & $\begin{array}{c}0.174 \\
(0.609)\end{array}$ \\
\hline Robbery & $\begin{array}{c}0.173 \\
(0.555)\end{array}$ & $\begin{array}{c}0.085 \\
(0.368)\end{array}$ & $\begin{array}{c}0.023 \\
(0.185)\end{array}$ \\
\hline Theft & $\begin{array}{c}2.759 \\
(4.125)\end{array}$ & $\begin{array}{l}1.356 \\
(2.699)\end{array}$ & $\begin{array}{c}0.361 \\
(1.172)\end{array}$ \\
\hline Vandalism & $\begin{array}{c}0.518 \\
(1.192)\end{array}$ & $\begin{array}{c}0.254 \\
(0.759)\end{array}$ & $\begin{array}{c}0.068 \\
(0.331)\end{array}$ \\
\hline
\end{tabular}

a Standard deviations are displayed in parentheses. 
Table A7: Dynamic Effects of Homicides on Block-Level Concealed-Carry Applications

\begin{tabular}{|c|c|c|c|c|c|c|c|}
\hline & 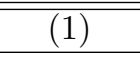 & $\overline{(2)}$ & 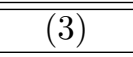 & $(4)$ & $(5)$ & $(6)$ & $\overline{(7)}$ \\
\hline \multicolumn{8}{|l|}{ Homicide Dummy Variable } \\
\hline Homicide five months after & & & & & & & $\begin{array}{l}-0.283 \\
(0.241)\end{array}$ \\
\hline Homicide four months after & & & & & & $\begin{array}{c}-0.574^{* *} \\
(0.290)\end{array}$ & $\begin{array}{r}-0.709^{* *} \\
(0.306)\end{array}$ \\
\hline Homicide three months after & & & & & $\begin{array}{c}0.159 \\
(0.235)\end{array}$ & $\begin{array}{c}0.115 \\
(0.241)\end{array}$ & $\begin{array}{c}0.096 \\
(0.244)\end{array}$ \\
\hline Homicide two months after & & & & $\begin{array}{l}-0.277 \\
(0.291)\end{array}$ & $\begin{array}{l}-0.235 \\
(0.287)\end{array}$ & $\begin{array}{l}-0.516 \\
(0.319)\end{array}$ & $\begin{array}{l}-0.376 \\
(0.328)\end{array}$ \\
\hline Homicide next month & & & $\begin{array}{c}0.182 \\
(0.242)\end{array}$ & $\begin{array}{c}0.192 \\
(0.244)\end{array}$ & $\begin{array}{c}0.210 \\
(0.270)\end{array}$ & $\begin{array}{c}0.213 \\
(0.281)\end{array}$ & $\begin{array}{c}0.238 \\
(0.303)\end{array}$ \\
\hline Homicide this month & & $\begin{array}{c}-0.057 \\
(0.235)\end{array}$ & $\begin{array}{l}-0.086 \\
(0.245)\end{array}$ & $\begin{array}{l}-0.055 \\
(0.257)\end{array}$ & $\begin{array}{l}-0.033 \\
(0.310)\end{array}$ & $\begin{array}{c}0.025 \\
(0.305)\end{array}$ & $\begin{array}{c}0.097 \\
(0.324)\end{array}$ \\
\hline Homicide last month & $\begin{array}{c}0.336^{* *} \\
(0.163)\end{array}$ & $\begin{array}{c}0.333^{* *} \\
(0.162)\end{array}$ & $\begin{array}{c}0.373^{* *} \\
(0.174)\end{array}$ & $\begin{array}{c}0.258 \\
(0.203)\end{array}$ & $\begin{array}{c}0.205 \\
(0.232)\end{array}$ & $\begin{array}{c}0.230 \\
(0.248)\end{array}$ & $\begin{array}{c}0.219 \\
(0.269)\end{array}$ \\
\hline Homicide two months prior & $\begin{array}{c}0.343^{*} \\
(0.178)\end{array}$ & $\begin{array}{c}0.339^{*} \\
(0.178)\end{array}$ & $\begin{array}{l}0.358^{*} \\
(0.208)\end{array}$ & $\begin{array}{c}0.268 \\
(0.234)\end{array}$ & $\begin{array}{c}0.264 \\
(0.249)\end{array}$ & $\begin{array}{c}0.267 \\
(0.267)\end{array}$ & $\begin{array}{c}0.282 \\
(0.297)\end{array}$ \\
\hline Homicide three months prior & $\begin{array}{c}0.120 \\
(0.217)\end{array}$ & $\begin{array}{c}0.116 \\
(0.219)\end{array}$ & $\begin{array}{c}0.094 \\
(0.223)\end{array}$ & $\begin{array}{c}0.083 \\
(0.251)\end{array}$ & $\begin{array}{c}0.181 \\
(0.245)\end{array}$ & $\begin{array}{c}0.175 \\
(0.257)\end{array}$ & $\begin{array}{c}0.196 \\
(0.270)\end{array}$ \\
\hline Month Fixed Effects & Yes & Yes & Yes & Yes & Yes & Yes & Yes \\
\hline Block by Year Fixed Effects & Yes & Yes & Yes & Yes & Yes & Yes & Yes \\
\hline City Trend & Yes & Yes & Yes & Yes & Yes & Yes & Yes \\
\hline Number of observations & 43,451 & 43,451 & 40,333 & 37,327 & 34,661 & 32,475 & 30,518 \\
\hline
\end{tabular}

Notes: The dependent variable is a census block's monthly number of new concealed-carry permit applications. Standard errors (in parentheses) are corrected for possible clustering at the block level.

$* 0.10, * * 0.05$ and ${ }^{* * *} 0.01$ denote significance levels. 
Table A8: Estimated Effects by Applicant Characteristics

\begin{tabular}{|c|c|c|c|c|c|c|c|c|}
\hline & (1) & $(2)$ & $(3)$ & $(4)$ & (5) & (6) & $(7)$ & $(8)$ \\
\hline & All & Black & White & Male & Female & Ages 21-39 & Ages 40-59 & Ages $60+$ \\
\hline Homicide previous two months & $\begin{array}{c}0.268^{* *} \\
(0.131)\end{array}$ & $\begin{array}{c}0.402 \\
(0.271)\end{array}$ & $\begin{array}{c}0.265 \\
(0.179)\end{array}$ & $\begin{array}{c}0.373^{* * *} \\
(0.142)\end{array}$ & $\begin{array}{l}-0.220 \\
(0.369)\end{array}$ & $\begin{array}{c}0.436^{* *} \\
(0.170)\end{array}$ & $\begin{array}{c}0.027 \\
(0.279)\end{array}$ & $\begin{array}{c}0.088 \\
(0.530)\end{array}$ \\
\hline Month FE & Yes & Yes & Yes & Yes & Yes & Yes & Yes & Yes \\
\hline Block by Year FE & Yes & Yes & Yes & Yes & Yes & Yes & Yes & Yes \\
\hline City Trend & Yes & Yes & Yes & Yes & Yes & Yes & Yes & Yes \\
\hline Number of observations & 46,112 & 9,200 & 39,307 & 41,247 & 13,918 & 23,433 & 23,607 & 11,288 \\
\hline
\end{tabular}

Notes: The dependent variable is a census block's monthly number of new concealed-carry permit applications. Standard errors (in parentheses) are corrected for possible clustering at the block level.

$* 0.10, * * 0.05$ and $* * * 0.01$ denote significance levels. 